\title{
Cannabinoid Signaling Recruits Astrocytes to Modulate Presynaptic Function in the Suprachiasmatic Nucleus
}

\author{
${ }^{\circledR}$ Lauren M. Hablitz, ${ }^{1,2}$ Ali N. Gunesch, ${ }^{1}$ Olga Cravetchi, ${ }^{1}{ }^{\circledR}$ Michael Moldavan, ${ }^{1}$ and ${ }^{\circledR}$ Charles N. Allen ${ }^{1,2}$
} https://doi.org/10.1523/ENEURO.0081-19.2020

${ }^{1}$ Oregon Institute of Occupational Health Sciences, Oregon Health \& Science University, Portland, OR 97239 and ${ }^{2}$ Department of Behavioral Neuroscience, Oregon Health and Science University, Portland, OR 97239

\section{Visual Abstract}

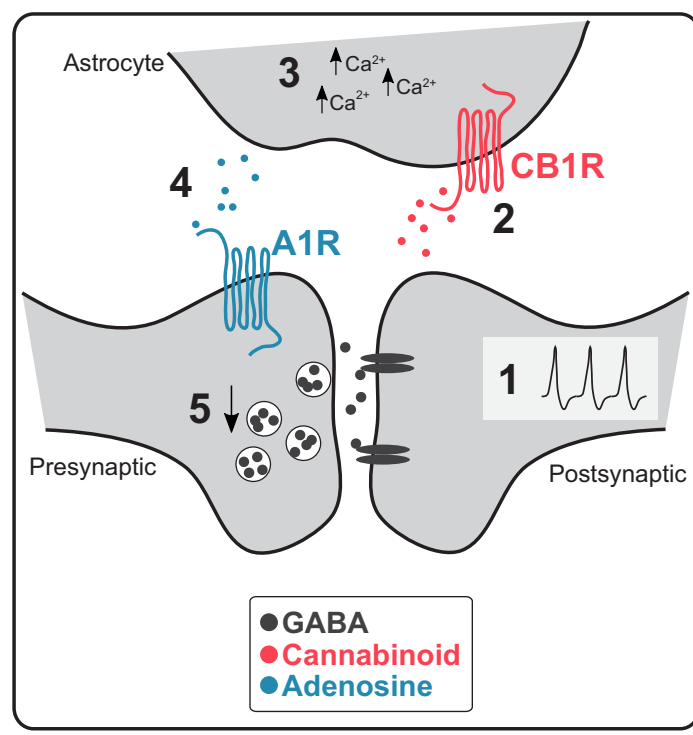

The Suprachiasmatic Nucleus

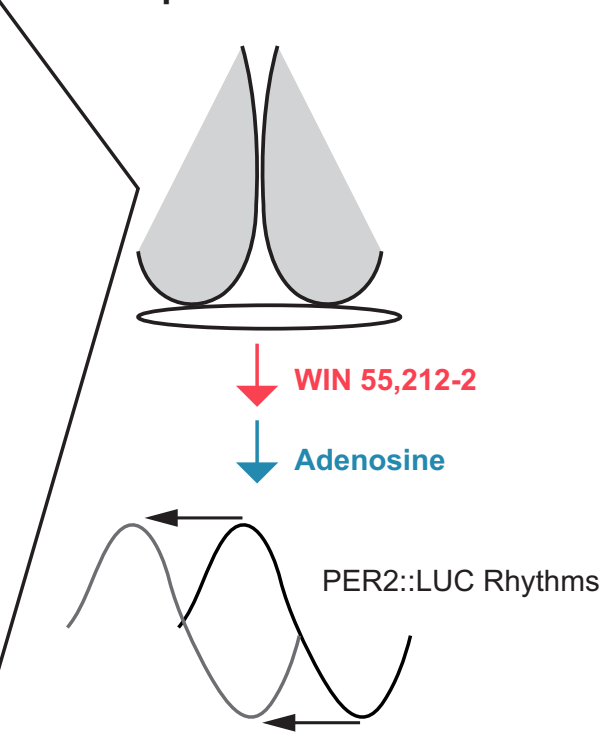

\section{Significance Statement}

Astrocytes are a critical component of the neural network in the suprachiasmatic nucleus (SCN) required for the generation of precise circadian rhythms. We hypothesized that postsynaptic SCN neurons recruit astrocytes via endocannabinoid signaling to modulate presynaptic GABA release. We demonstrate, using a combination of approaches including whole-cell patch-clamp electrophysiology, GCaMP6 calcium imaging in astrocytes, pharmacology, and manipulation of intracellular signaling cascades using designer receptors exclusively activated by designer drug (DREADD) technology, that SCN neurons release cannabinoids that activate astrocyte intracellular $\mathrm{Ca}^{2+}$ signaling pathways to modulate GABA neurotransmission via adenosine. In addition to unraveling this novel signaling cascade in the SCN, we demonstrate that both CB1 receptor activation and adenosine phase advance the molecular circadian clock, suggesting an important role for astrocytes in modulating clock timing. 
Circadian rhythms are 24-h cycles in physiology regulated by the suprachiasmatic nucleus (SCN) in the brain, where daily cues act on SCN neurons to alter clock timing. Cannabinoid signaling modulates SCN neuronal activity, although the mechanism remains unclear. We propose that neuronal activity generates endocannabinoid release, activating astrocyte $\mathrm{Ca}^{2+}$ signaling, which releases adenosine and activates adenosine-1 receptors (A1Rs) on the presynaptic axon terminals, decreasing GABA release. We demonstrated, in mice, that activation of cannabinoid-1 receptors (CB1R) with the agonist WIN 55,212-2 (WIN) reduced the miniature GABA receptormediated postsynaptic current (mGPSC) frequency by a mechanism that requires astrocytes and A1R. WIN activated an intracellular $\mathrm{Ca}^{2+}$ signaling pathway in astrocytes. Activating this intracellular $\mathrm{Ca}^{2+}$ pathway with designer receptors exclusively activated by designer drugs (DREADDs) also decreased the mGPSC frequency and required $A 1 R$ activation. The frequency of spontaneous $\mathrm{Ca}^{2+}$ events, including those induced by depolarization of a postsynaptic SCN neuron, was reduced by blocking CB1R activation with AM251, demonstrating neuronal endocannabinoid signaling modulates astrocytic $\mathrm{Ca}^{2+}$ signaling in the SCN. Finally, daytime application of WIN or adenosine phase advanced the molecular circadian clock, indicating that this cannabinoid signaling pathway is vital for the timing of circadian rhythms.

Key words: astrocyte; circadian rhythm; endocannabinoid; GABA; suprachiasmatic nucleus

\section{Introduction}

Circadian rhythms are 24-h cycles in behavioral and physiologic processes such as sleep/wake cycles, cognitive function, and hormone release. In mammals, the master circadian oscillator is located in the suprachiasmatic nucleus (SCN) where neurons expressing a molecular clock generate a 24-h timing signal. The network of SCN neurons and astrocytes, which also express molecular clocks, are required for a precise and stable circadian signal (Welsh et al., 2010; Jackson, 2011; Mohawk and Takahashi, 2011). A single astrocyte can interact with hundreds of synapses, enabling these cells to regulate network activity within brain regions (Pirttimaki and Parri, 2013). Astrocytes regulate clock gene expression and neuronal synchrony in culture systems, but how astrocytes regulate neuronal function within the SCN remains largely unknown (Beaulé et al., 2009; Marpegan et al., 2009, 2011; Barca-Mayo et al., 2017; Brancaccio et al., 2017; Tso et al., 2017; Svobodova et al., 2018). Astrocytes

Received March 6, 2019; accepted January 13, 2020; First published January 21, 2020.

The authors declare no competing financial interests.

Author contributions: L.M.H. and C.N.A. designed research; L.M.H., A.N.G., O.C., and M.M. performed research; L.M.H., A.N.G., O.C., M.M., and C.N.A. analyzed data; L.M.H. and C.N.A. wrote the paper.

This work was supported by National Institutes of Health $(\mathrm{NIH})$ Grants NS036607 and NS103842 (to C.N.A.), an Oregon Institute of Occupational Health Sciences Summer Student Research Award (A.N.G.), and the National Institute on Drug Abuse Training Grant Postdoctoral Fellowship T32DA007262 (to L.M.H.). The imaging work was supported by the NIH Grant P30 NS061800 and used resources in the Advanced Light Microscopy Core at The Jungers Center acquired under NIH Grant S10 RR025440.

Acknowledgements: We thank Dr. Piotr Bregestovski for kindly providing us with the Cre-inducible Rosa26::Cl-Sensor mice and Mike Lasarev for help with statistical analysis.

L. M. Hablitz's present address: Center for Translational Neuromedicine, Department of Neurosurgery, University of Rochester Medical Center, Rochester, NY 14642

Correspondence should be addressed to Charles N. Allen at allenc@ohsu.edu.

https://doi.org/10.1523/ENEURO.0081-19.2020

Copyright $\odot 2020$ Hablitz et al.

This is an open-access article distributed under the terms of the Creative Commons Attribution 4.0 International license, which permits unrestricted use, distribution and reproduction in any medium provided that the original work is properly attributed. regulate neuronal function in multiple ways, from buffering extracellular ion and neurotransmitter concentrations (Bellot-Saez et al., 2017), to regulating blood oxygen and metabolism (Sonnay et al., 2018; Takata et al., 2018), and actively responding to external cues through intracellular signaling molecules such as $\mathrm{Ca}^{2+}$ and inducing the release of neuromodulators such as ATP, glutamate, or adenosine (Fiacco et al., 2009; Losi et al., 2014).

Endocannabinoids, endogenously generated lipophilic molecules, act as retrograde signals from neurons to regulate presynaptic neurotransmitter release via activation of G-protein-coupled cannabinoid-1 receptors (CB1Rs; Ohno-Shosaku et al., 2001; Wilson et al., 2001; Wilson and Nicoll, 2001; Araque et al., 2017). The production and metabolism of endocannabinoids have diurnal patterns, indicating they may be under circadian clock control (Valenti et al., 2004; Liedhegner et al., 2014; Koch et al., 2015). Cannabinoid receptor activation blocks lightinduced phase shifts of circadian behavior (Sanford et al., 2008; Acuna-Goycolea et al., 2010). In addition, cannabinoid signaling increases neuronal firing within the SCN by decreasing presynaptic GABA release (Acuna-Goycolea et al., 2010). Given this evidence of interactions between the circadian and cannabinoid systems, surprisingly little is known about how cannabinoids alter SCN function and circadian clock timing. Endocannabinoids can alter neuronal function by activating astrocyte signaling pathways and the release of gliotransmitters (Navarrete and Araque, 2008). Here, we hypothesize that cannabinoid signaling activates an intracellular $\mathrm{Ca}^{2+}$ signaling pathway in astrocytes and releases neuromodulators to alter SCN neuronal function and ultimately change circadian clock timing.

\section{Materials and Methods}

\section{Ethical approval}

All animal care, handling, and housing were approved in advance by the Institutional Animal Care and Use Committee at Oregon Health \& Science University.

\section{Animals and housing}

Both male and female mice (three to six months of age) on a C57/BL6 background were used. Mice were group housed on a 12/12 h light/dark (LD) cycle with food 
and water ad libitum. GFAP-Cre mice (B6.Cg-Tg(Gfapcre)73.12Mvs/J; The Jackson Laboratory, RRID:IMSR JAX:012886), where Cre recombinase expression is driven by the promotor for the astrocytic marker glial fibrillary acidic protein (GFAP), were used to target expression to SCN astrocytes. Tail samples were sent to an external facility for genotyping (Transnetyx, Inc).

\section{Electrophysiology}

Mice were terminally anesthetized between zeitgeber time (ZT)3 and ZT5 (ZT12 defined as lights off) with isoflurane followed by cervical dislocation and decapitation. All recordings were made between projected ZT7- ZT10. Brains were harvested, sectioned, and recorded using the patch clamp technique. Experimental treatments included WIN 55,212-2 (WIN; $3 \mu \mathrm{M}$; Sigma-Aldrich), AM251 (5 $\mu \mathrm{M}$; Tocris), fluorocitrate (FC; $1 \mu \mathrm{M}$; Sigma-Aldrich), ACPT-II (200 $\mu \mathrm{M}$; Tocris), CGS15943 (50 $\mu \mathrm{M}$; Tocris), DPCPX (0.2 $\mu \mathrm{M}$; Tocris), clozapine-N-oxide (CNO; $10 \mu \mathrm{M}$; Cayman Chemical), thaspsigargin ( $1 \mu \mathrm{M}$; Tocris), and adenosine (100 $\mu \mathrm{M}$; Sigma-Aldrich). All miniature GABA(A) receptormediated postsynaptic currents (mGPSC; for rationale behind terminology, see Chavas and Marty, 2003; Woodin et al., 2003) recordings were performed in the presence of TTX (1 $\mu \mathrm{M}$; Tocris) and CNQX (10 $\mu \mathrm{M}$; Tocris) to block action potential driven synaptic transmission. During electrophysiological recordings, cells were voltageclamped at $-60 \mathrm{mV}$ to ensure inward GABA currents. The microelectrode internal solution consisted of the following: $150 \mathrm{mM} \mathrm{KCl}, 20 \mathrm{mM}$ HEPES, and $5 \mathrm{mM}$ dextrose. Slicing solution consisted of the following: $111 \mathrm{mM}$ $\mathrm{NaCl}, 6 \mathrm{mM} \mathrm{Na}$ (gluconate), $3 \mathrm{mM} \mathrm{KCl}, 1 \mathrm{mM} \mathrm{Na}_{2} \mathrm{H}_{2} \mathrm{PO}_{4}, 4$ $\mathrm{mM} \mathrm{MgCl} 2 \cdot 6 \mathrm{H}_{2} \mathrm{O}, 26 \mathrm{mM} \mathrm{NaHCO}_{3}, 11 \mathrm{mM}$ dextrose, and $0.5 \mathrm{mM} \mathrm{CaCl}_{2} \cdot 2 \mathrm{H}_{2} \mathrm{O}$. Recording solution consisted of the following: $114 \mathrm{mM} \mathrm{NaCl}, 6 \mathrm{mM} \mathrm{Na}$ (gluconate), $2.7 \mathrm{mM} \mathrm{KCl}, 1$ $\mathrm{mM} \mathrm{Na} \mathrm{H}_{2} \mathrm{PO}_{4}, 1 \mathrm{mM} \mathrm{MgCl} 2.6 \mathrm{H}_{2} \mathrm{O}, 26 \mathrm{mM} \mathrm{NaHCO}, 11 \mathrm{mM}$ dextrose, and $2 \mathrm{mM} \mathrm{CaCl} 2 \cdot 2 \mathrm{H}_{2} \mathrm{O}$. Baseline mGPSC frequency was defined as the average of three 20-s epochs before drug treatment. mGPSC analysis was performed using lgor Pro 7 (Wavemetrics) and data are presented as mean \pm SEM. FC was applied to the slice 5 min before recording from a neuron, with a total treatment duration of $\sim 45 \mathrm{~min}$. To reduce the possible physiologic damage to astrocytes produced by multiple FC exposures: after recording the response of a single neuron to FC application the FC was washed from the bath, the treated slice replaced with a naive slice, and a new experiment performed.

\section{Immunohistochemistry}

Each mouse was deeply anesthetized with isoflurane and transcardially perfused with phosphate buffered saline $1 \times$ (PBS), $\mathrm{pH} 7.4$, followed by $4 \%$ paraformaldehyde (PFA) in PBS. After perfusion, the brain was postfixed in PFA for $18 \mathrm{~h}$ at $4^{\circ} \mathrm{C}$ and cryoprotected by incubating overnight at $4^{\circ} \mathrm{C}$ first in $10 \%$ then $30 \%$ sucrose in PBS. Brain blocks were embedded in Shandon Cryochrome embedding medium (Thermo Fisher Scientific Inc.) and fast-frozen by dry ice mixed with $96 \%$ ethanol for 3-5 min. Coronal (20 $\mu \mathrm{m}$ thick) sections were cut with a Leica cryostat (CM1950, Leica Microsystems, Inc.), thaw- mounted onto pre-cleaned SuperFrost Plus glass slides, and dried at $37^{\circ} \mathrm{C}$. Air-dried SCN-containing sections were hydrated in $0.1 \mathrm{M} \mathrm{PB}$. To reduce background autofluorescence, the sections were incubated in an aldehyde-reducing agent $1 \% \mathrm{NaBH}_{4}$ in $0.1 \mathrm{M}$ PB for 30 min and rinsed copiously with multiple changes of $0.1 \mathrm{M}$ PB until there were no signs of bubbles. The tissue was permeabilized with $0.3 \%$ Triton X-100 in TBS and nonspecific binding was blocked by incubation in $5 \%$ normal donkey serum for $1 \mathrm{~h}$ at room temperature. For GFAP staining, the primary antibody was mouse anti-GFAP (1: 1000, Millipore Bioscience Research Reagents MAB 3402, RRID:AB_94844). The secondary antibody was donkey anti-mouse Dy-Light 594 (1:1000, Jackson ImmunoResearch \#715-585-151, RRID:AB_2340855). For neurofilament heavy chain (NFHC), primary antibody was chicken polyclonal anti-NFHC (1:500, Aves Labs, catalog \#NFH, RRID: $\left.A B \_2313552\right)$. The secondary antibody was donkey antichicken/CF 488A (1:500, Sigma SAB4600031, RRID: AB_2721061). For the neural/glial antigen-2 (NG2) staining, the primary antibody was mouse monoclonal anti-NG2 (1:250, Abcam catalog \#ab50009, RRID: $\left.A B \_881569\right)$. The secondary antibody was donkey antimouse Dy-Light 594 (1:1000, Jackson ImmunoResearch \#715-585-151, RRID:AB_2340855).

\section{Stereotaxic surgery}

Male and female GFAP-Cre mice were anesthetized with isoflurane and fixed in a stereotaxic frame. Next, two 90-nl boluses, $30 \mathrm{~s}$ apart of either AAV9.CAG.Flex. GCaMP6m.WPRE.SV40 (Penn Vector Core), AAV5-DIOhM3Dq-mCherry (Addgene), or an equal mixture were bilaterally injected into the SCN to coordinates: $x,-0.4, y$, \pm 0.2 , and $z,-5.8$ from bregma. SCN $(150 \mu \mathrm{m})$ slices were prepared on days 10-21 after injection as described above. Successful injections were confirmed by observing expression of the green reporter GCaMP6 or mCherry expression from the Gq DREADD in the SCN.

\section{Calcium imaging}

$\mathrm{Ca}^{2+}$ measurements were obtained by recording images at an excitation wavelength of $380 \mathrm{~nm}$ supplied via a Lambda 10-3 filter wheel (Sutter Instrument Company) passing through a UG11 optical filter to restrict harmonic wavelengths above $400 \mathrm{~nm}$, reflected via a 400-nm DCLP dichroic mirror, and through a Leica $40 \times / 0.80$ UV water immersion objective (Leica Biosystems). Emitted light passed through a $510 \pm 40 \mathrm{~nm}$ filter (Chroma Technology) and was recorded with a cooled charge-coupled device camera (CCD-1300-Y/HS, Princeton Scientific) with acquisition time and binning adjusted to minimize photobleaching and maximize recording speed via the digital imaging software Metafluor (Molecular Devices).

To record the long-term changes in $\left[\mathrm{Ca}^{2+}\right]$ i due to bath application of WIN, images were sampled every $10 \mathrm{~s}$. This was chosen based on previous work investigating $\mathrm{Ca}^{2+}$ signaling in cortical astrocytes, which demonstrated that most agonist-induced events lasted longer than $10 \mathrm{~s}$ (Poskanzer and Yuste, 2016). Regions of interest (ROls) were selected based on visual identification of independent intensity differences from the rest of the slice. To 

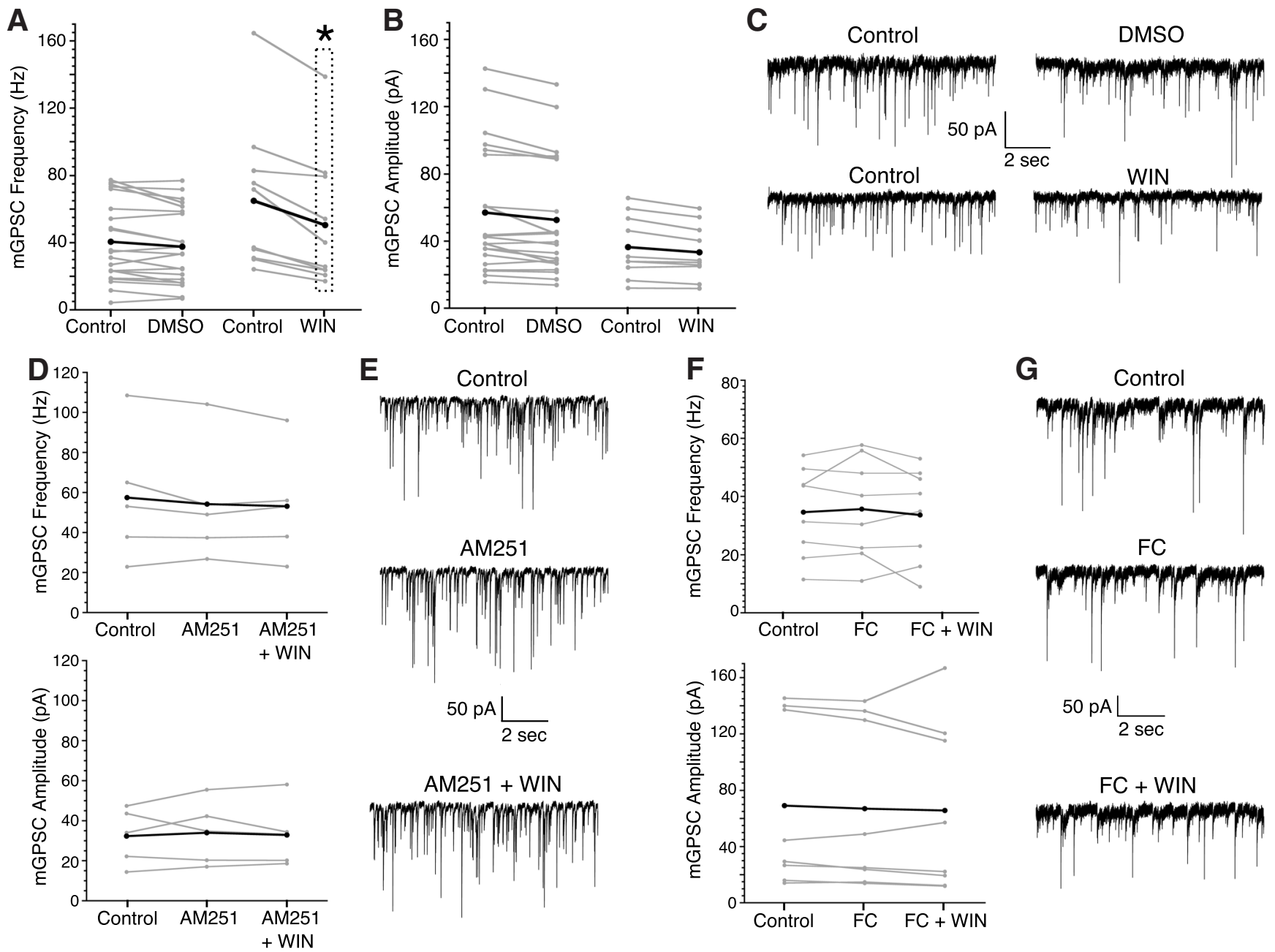

Figure 1. WIN decreases mGPSC frequency in a CB1R and astrocyte-dependent manner. For all frequency and amplitude plots gray lines are individual cells, black lines indicate the group average. $\boldsymbol{A}$, Individual cell and mean mGPSC frequencies before and after treatment with either DMSO $(0.01 \%)$ or WIN $(3 \mu \mathrm{M})$. B , Individual cell and mean amplitudes of mGPSCs before and after DMSO or WIN application. $\boldsymbol{C}$, Representative mGPSC current recordings before and after treatment with DMSO or WIN. $\boldsymbol{D}$, Individual cell and mean mGPSC frequency (top) and amplitude (bottom) pretreatment, with AM251 (5 $\mu \mathrm{M})$, and with both AM251 (5 $\mu \mathrm{M})$ and WIN (3 $\mu \mathrm{M})$. $\boldsymbol{E}$, Representative mGPSC recordings from a single neuron before and during treatment, with AM251, and with AM251 and WIN. $\boldsymbol{F}$, Individual cell mGPSC frequency (top) and amplitude (bottom) before and during application of FC (1 $\mu \mathrm{M})$, and with both FC (1 $\mu \mathrm{M})$ and WIN $(3 \mu \mathrm{M})$. G, Representative mGPSC recordings from a single neuron before and during treatment with FC, and with FC and WIN; $* p<0.001$, repeated measures analysis.

evaluate changes of $\mathrm{ROI}$ intensity after drug treatment, the baseline was defined as the $300 \mathrm{~s}$ before test agent application. $\Delta \mathrm{F} / \mathrm{F}=(\mathrm{ROI}$ intensity-baseline intensity $) /$ baseline intensity. To eliminate experimenter bias in defining a positive or negative response, drug-induced change in $\mathrm{Ca}^{2+}$ was defined as a $\Delta F / F>2$ SD away from baseline (Poskanzer and Yuste, 2016).

In separate experiments measuring faster, spontaneous $\mathrm{Ca}^{2+}$ events, and for paired electrophysiological recordings and GCaMP imaging of spontaneous $\mathrm{Ca}^{2+}$ events, images were acquired every $2 \mathrm{~s}$, based on previous work in the SCN investigating spontaneous $\mathrm{Ca}^{2+}$ signals (Brancaccio et al., 2017), and to enable better resolution for washout experiments without photobleaching the epifluorescence. For these experiments, $\Delta \mathrm{F} / \mathrm{F}=\mathrm{ROI}$ intensity/ average slice intensity. Average slice intensity was used to eliminate large baseline shifts in intensity on drug treat- ment that may have been due to decreasing CB1R activity with AM251, or by photobleaching produced by the higher acquisition rate. An event was defined as a time point that was $>2$ SD away from the average intensity of the previous $30 \mathrm{~s}$.

\section{Bioluminescence assays}

Long-term organotypic slice cultures of the SCN were prepared from PER2::LUC mice. These slices allow for long-term recording of molecular clock rhythms that follow stable patterns of expression throughout the entire recording session, indicating that the SCN network remains largely intact (Yoo et al., 2004). Slices were treated within the first $4 \mathrm{~d}$ in the early subjective day, circadian time (CT)1-CT6 (where CT 12 is defined as peak bioluminescence), for $1 \mathrm{~h}$ with $3 \mu \mathrm{M}$ WIN (Sigma-Aldrich), 0.09\% DMSO, $0.2 \mu \mathrm{M}$ DPCPX, a combination treatment of WIN 
Table 1. mGPSC frequency data $(\mathrm{Hz})$ for whole-cell electrophysiology experiments

\begin{tabular}{|c|c|c|c|c|c|c|c|c|c|c|}
\hline \multicolumn{11}{|c|}{ Frequency $(\mathrm{Hz})$} \\
\hline \multirow{3}{*}{$\begin{array}{l}\text { Treatment } 1 \\
\text { Mean }\end{array}$} & \multicolumn{6}{|c|}{ Group means } & \multicolumn{4}{|c|}{ Mean of within cell ratio } \\
\hline & \multicolumn{2}{|c|}{ Control } & \multicolumn{2}{|c|}{ Treatment 1} & \multicolumn{2}{|c|}{ Treatment 2} & \multicolumn{2}{|c|}{$\begin{array}{l}\text { Treatment 1/ } \\
\text { control }\end{array}$} & \multicolumn{2}{|c|}{$\begin{array}{c}\text { Treatment 2/ } \\
\text { control }\end{array}$} \\
\hline & SEM & Mean & SEM & Mean & SEM & Mean & SEM & Mean & SEM & \\
\hline DMSO & 40.57 & 5.22 & 37.64 & 4.87 & - & - & 0.95 & 0.04 & - & - \\
\hline WIN & 64.98 & 13.77 & 50.50 & 12.36 & - & - & 0.74 & 0.04 & - & - \\
\hline CNO & 48.56 & 11.04 & 41.07 & 10.01 & - & - & 0.82 & 0.04 & - & - \\
\hline Adenosine & 42.03 & 4.63 & 33.75 & 3.80 & - & - & 0.79 & 0.05 & - & - \\
\hline \multicolumn{11}{|c|}{ Treatment 2: WIN (3 $\mu \mathrm{M})$} \\
\hline AM251 & 57.46 & 14.60 & 54.22 & 13.32 & 53.14 & 12.32 & 0.97 & 0.06 & 0.95 & 0.03 \\
\hline $\mathrm{FC}$ & 34.70 & 5.46 & 35.78 & 6.13 & 33.73 & 5.67 & 1.02 & 0.04 & 0.98 & 0.09 \\
\hline ACPTII & 34.14 & 5.07 & 32.86 & 5.08 & 28.30 & 4.65 & 0.96 & 0.03 & 0.81 & 0.04 \\
\hline CGS & 38.78 & 8.25 & 38.50 & 6.93 & 36.86 & 6.53 & 1.04 & 0.05 & 1.00 & 0.05 \\
\hline DPCPX & 44.92 & 4.83 & 42.29 & 4.77 & 42.48 & 5.40 & 0.94 & 0.03 & 0.99 & 0.06 \\
\hline \multicolumn{11}{|c|}{ Treatment 2: CNO $(10 \mu \mathrm{M})$} \\
\hline DPCPX & 39.08 & 3.25 & 37.87 & 3.79 & 34.83 & 3.01 & 0.96 & 0.04 & 0.94 & 0.07 \\
\hline
\end{tabular}

The treatment/control ratio was calculated for each recorded neuron and then averaged for each treatment group.

and DPCPX, $100 \mu \mathrm{M}$ adenosine (Sigma-Aldrich), or $0.38 \%$ sterile water. Data were acquired and analyzed with Lumicycle Analysis software (Actimetrics, Inc). Baseline drift in Lumicycle recordings was corrected by subtracting a third order or less polynomial followed by fitting with a damped sine wave. Only recordings with $>75 \%$ goodness-of-fit to a dampened sine wave were used for analysis. Phase shifts were calculated by comparing two predictions for the time of the first peak post-treatment: one prediction calculated from at least three cycles before treatment and a second prediction derived from at least three cycles after treatment. The difference between these two predictions indicated the size of the phase shift (Besing et al., 2012; Hablitz et al., 2014).

\section{Statistical analysis}

All statistical analysis was performed with PASW Statistics 18 (IBM Analytics). For comparisons of means in samples with normal distributions and homogeneous variances (as indicated by a Levene's test), an independent samples $t$ test or ANOVA was used for comparisons between two means or two or more means, respectively, followed by Fisher's Bonferroni adjusted post hoc test when necessary. In cases of a non-normal distribution (as indicated by a Shapiro-Wilk test) or unequal variances (Levene's test), a nonparametric Mann-Whitney $U$ test or Kruskal-Wallis test was used for comparisons between two means or two or more means, respectively, followed by a median test for post hoc analyses. Significance was ascribed at $p<0.05$. A repeated measures analysis was used for change over time within a cell or a slice, when appropriate. In the case of a non-normal distribution, a Friedman test followed by post hoc Wilcoxon signed-rank tests with the alpha level Bonferroni adjusted for multiple comparisons was used.

\section{Results}

\section{WIN causes astrocyte-dependent changes in mGPSC frequency}

The CB1/2R agonist WIN was used to examine the effect of CB1/2R activation on mGPSC frequency in the
SCN (Fig. 1). Bath application of WIN (3 $\mu \mathrm{M})$ significantly decreased the mGPSC frequency but not amplitude compared to DMSO $(0.01 \%)$ controls (WIN: $-25.6 \pm 3.6 \%$ vs DMSO: $-5.2 \pm 4.3 \%$, Fig. $1 A-C$; for frequency and amplitude averages and normalized averages, see Tables 1, 2 for statistical test results, see Table 3). The CB1R antagonist, AM251 (5 $\mu \mathrm{M})$ completely blocked the WIN-induced reduction of the mGPSC frequency (AM251+WIN: $-5.3 \pm$ $3.1 \%$ ). AM251 alone did not significantly change the mGPSC frequency or amplitude compared to 0.01\% DMSO controls (Fig. 1D,E; Tables 1-Tables 3). These data are consistent with previous work demonstrating CB1R mediated inhibition of GABA release from presynaptic terminals (Acuna-Goycolea et al., 2010).

After demonstrating that WIN decreases the frequency of mGPSCs, we next sought to determine whether astrocytes played a role in cannabinoid signaling. Astrocytic metabolic function was inhibited with FC (1 $\mu \mathrm{M})$, an inhibitor of the Krebs cycle preferentially taken up by astrocytes (Navarrete and Araque, 2008). FC application did not significantly change mGPSC frequency or amplitude compared to $0.01 \%$ DMSO controls (Fig. $1 F, G$ ). However, FC completely occluded the WIN reduction of the mGPSC frequency ( $\mathrm{FC}+\mathrm{WIN}:-2.0 \pm 8.58 \%)$, and had no effect on the mGPSC amplitude, indicating that proper astrocytic functioning was necessary for the presynaptic effects of WIN (Fig. 1F,G; Tables 1-Tables 3).

\section{The CB1/2R agonist WIN induces an increase in intracellular astrocytic $\mathbf{C a}^{2+}$}

To understand how cannabinoids influence astrocyte signaling, we targeted astrocytes by using a mouse line where Cre recombinase expression is driven by the astrocytic marker GFAP. To validate the specificity of the Cre recombinase expression to astrocytes in the SCN, we bred GFAP-Cre mice with the chloride sensor ( $\mathrm{Cl}^{-}$sensor) mouse line, a chloride reporter that has robust expression and a strong fluorescent signal (Waseem et al., 2010; Klett and Allen, 2017). We then compared the expression of the $\mathrm{Cl}^{-}$sensor to that of neuronal and glial cells markers in the SCN. The GFAP staining and fluorescent $\mathrm{Cl}^{-}$sensor signal 
Table 2. mGPSC amplitude data (pA) for the whole-cell electrophysiology experiments

\begin{tabular}{|c|c|c|c|c|c|c|c|c|c|c|}
\hline \multicolumn{11}{|c|}{ Amplitude (pA) } \\
\hline & \multicolumn{6}{|c|}{ Group means } & \multicolumn{4}{|c|}{ Mean of within cell ratio } \\
\hline DMSO & 45.75 & 8.88 & 43.41 & 8.01 & - & - & 0.92 & 0.02 & - & - \\
\hline WIN & 36.76 & 6.55 & 34.06 & 5.70 & - & - & 0.93 & 0.02 & - & - \\
\hline CNO & 39.88 & 8.40 & 39.20 & 7.53 & - & - & 1.03 & 0.07 & - & - \\
\hline AM251 & 34.85 & 7.38 & 37.40 & 8.03 & 32.90 & 7.08 & 1.06 & 0.09 & 1.04 & 0.10 \\
\hline $\mathrm{FC}$ & 72.48 & 27.41 & 70.96 & 25.97 & 65.65 & 21.34 & 0.96 & 0.03 & 0.91 & 0.07 \\
\hline ACPTII & 45.31 & 7.99 & 43.76 & 7.02 & 41.32 & 6.20 & 0.99 & 0.03 & 0.96 & 0.05 \\
\hline CGS & 48.69 & 10.49 & 48.96 & 10.34 & 46.40 & 10.30 & 1.01 & 0.02 & 0.94 & 0.03 \\
\hline DPCPX & 61.72 & 14.98 & 57.29 & 13.14 & 55.12 & 11.72 & 0.96 & 0.03 & 0.92 & 0.04 \\
\hline \multicolumn{11}{|c|}{ Treatment 2: CNO $(10 \mu \mathrm{M})$} \\
\hline
\end{tabular}

The treatment/control ratio was calculated for each recorded neuron and then averaged for each treatment group.

co-localized completely (Fig. 2A-F). $\mathrm{Cl}^{-}$sensor expression was not detected in cells positive for NFHC (Fig. 2G-L) or the Neural/Glial antigen proteoglycan (data not shown), a marker for polydenrocyte glia (Nishiyama et al., 2009). Note that NFHC was used instead of more commonly used neuronal markers, such as neuronal nuclear antigen and neuron specific enolase, which are barely detectable in SCN neurons (Morin et al., 2011; Moldavan et al., 2015). These data demonstrate that the GFAP-Cre mice are an appropriate model to target astrocytes in the SCN.

Endocannabinoids recruit astrocytes to mediate synaptic transmission by initiating intracellular $\mathrm{Ca}^{2+}$ signaling cascades (Navarrete and Araque, 2010; Bindocci et al., 2017). Here, we tested the hypothesis that activation of CB1/2Rs activates an intracellular $\mathrm{Ca}^{2+}$ signaling pathway in SCN astrocytes (Fig. 3). An adeno-associated virus containing GCaMP6, an intensity based $\mathrm{Ca}^{2+}$ reporter that is flanked by loxP sites (Chen et al., 2013), was injected into the SCN of GFAP-Cre+ animals to enable monitoring of $\mathrm{Ca}^{2+}$ signaling in SCN astrocytes. Astrocyte regions were defined as soma or non-soma by shape; somas were identified as more circular with thin processes branching from the center. This distinction was made because astrocytes differentially, spatiotemporally, regulate $\mathrm{Ca}^{2+}$ influxes throughout their somas and processes (Shigetomi et al., 2013; Tong et al., 2013; Bindocci et al., 2017). Increases or decreases of intracellular $\mathrm{Ca}^{2+}$ were defined as events if the amplitude was $>2$ SD from baseline, with variable responses showing both a significant increase and a significant decrease (Irwin and Allen, 2013). WIN (3 $\mu \mathrm{M})$ application increased $\left[\mathrm{Ca}^{2+}\right] \mathrm{i}$ in $52.5 \%$ of the somas. The non-soma regions showed similar responses with increased $\left[\mathrm{Ca}^{2+}\right] \mathrm{i}$ in $55.2 \%$ (Fig. 3B,F). Controls were treated with $0.01 \%$ DMSO, the concentration

Table 3. Statistics for the data shown in Figures 1-Figures 3

\begin{tabular}{|c|c|c|c|}
\hline Figure & Statistical test & Statistics output & $N$ \\
\hline Fig. $1 A, B$ & & & WIN: 10 neurons, 4 mice, DMSO: 21 neurons, 7 mice \\
\hline mGPSC frequency: DMSO $\times$ WIN & ANOVA & $F_{(1,28)}=14.704, p=0.001$ & \\
\hline mGPSC amplitude: DMSO $\times$ WIN & ANOVA & $F_{(1,29)}=0.598, p=0.445$ & \\
\hline Fig. $1 D$ & & & AM251: 5 neurons, 3 mice \\
\hline mGPSC frequency: DMSO $\times$ AM251 & ANOVA & $F_{(1,30)}=1.153, p=0.292$ & \\
\hline mGPSC amplitude: DMSO $\times$ AM251 & ANOVA & $F_{(1,30)}=2.975, p=0.095$ & \\
\hline mGPSC frequency: AM251 × AM251 + WIN & $\begin{array}{l}\text { Repeated measures } \\
\text { ANOVA }\end{array}$ & $F_{(2,8)}=1.719, p=0.239$ & \\
\hline Fig. $1 F$ & & & FC: 8 neurons, 3 mice \\
\hline mGPSC frequency: DMSO $\times$ FC & ANOVA & $F_{(1,28)}=3.52, p=0.071$ & \\
\hline Fig. $3 A, B, E, F$ & & & WIN: 4 mice, 6 slices, 38 soma (s), 194 non-soma (ns) \\
\hline Increase magnitude: treatment $(\mathrm{WIN} / \mathrm{DMSO}) \times \mathrm{ROI}(\mathrm{s} / \mathrm{ns})$ & Kruskal-Wallis & $H(3)=169.052, p<0.001$ & DMSO: 3 mice, 4 slices, 70 s, 86 ns \\
\hline Increase magnitude DMSO: $\mathrm{s} \times \mathrm{ns}$ & Median post hoc & $p=1$ & \\
\hline Increase magnitude WIN: $\mathrm{s} \times \mathrm{ns}$ & Median post hoc & $p=1$ & \\
\hline Increase magnitude (both $\mathrm{s}$ and ns): DMSO $\times$ WIN & Median post hoc & $p<0.001$ & \\
\hline Decrease magnitude: treatment $(\mathrm{WIN} / \mathrm{DMSO}) \times \mathrm{ROI}(\mathrm{s} / \mathrm{ns})$ & Kruskal-Wallis & $\mathrm{H}(3)=60.729, p<0.001$ & \\
\hline Decrease magnitude DMSO: $\mathrm{s} \times \mathrm{ns}$ & Median post hoc & $p=1$ & \\
\hline Decrease magnitude WIN: $\mathrm{s} \times \mathrm{ns}$ & Median post hoc & $p=1$ & \\
\hline Increase magnitude (both s and ns): DMSO $\times$ WIN & Median post hoc & $p<0.01$ & \\
\hline Fig. $3 C, G$ & & & TTX + CNQX + WIN: 4 mice, 5 slices, $19 \mathrm{~s}, 93 \mathrm{~ns}$ \\
\hline Increase magnitude: treatment $(\mathrm{WIIN} / \mathrm{TTX}+\mathrm{CNQX}+\mathrm{WIN}) \times \mathrm{ROI}(\mathrm{s} / \mathrm{ns})$ & Kruskal-Wallis & $H(3)=13.35, p=0.004$ & \\
\hline Increase magnitude ns: WIN $\times T T X+C N Q X+$ WIN & Median post hoc & $p=0.017$ & \\
\hline Decrease magnitude: treatment $(\mathrm{WIIN} / \mathrm{TTX}+\mathrm{CNQX}+\mathrm{WIN}) \times \mathrm{ROI}(\mathrm{s} / \mathrm{ns})$ & Kruskal-Wallis & $H(3)=2.213, p=0.529$ & \\
\hline
\end{tabular}



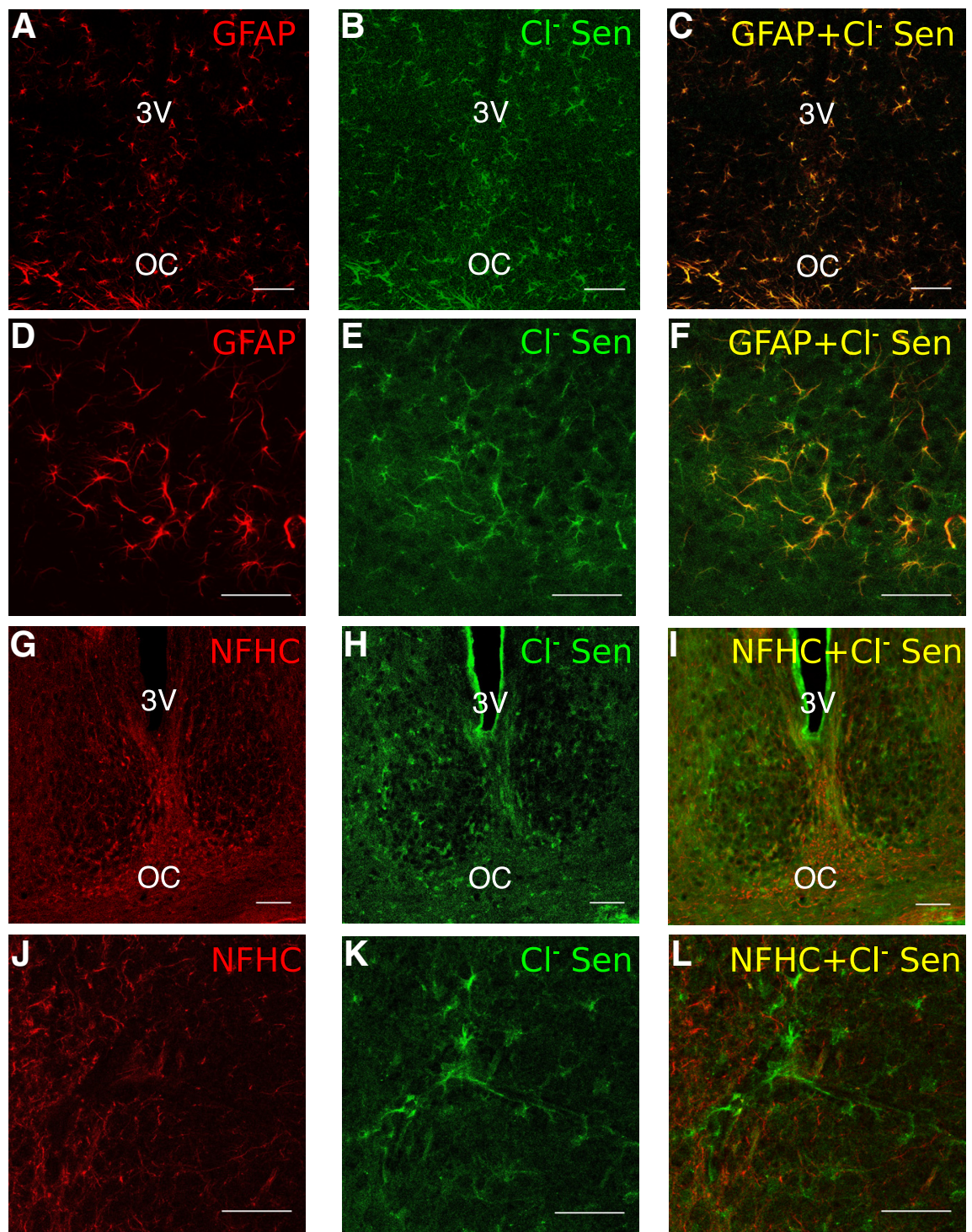

Figure 2. Chloride sensor expression in GFAP-Cre+ animals is specific to GFAP expressing astrocytes and not neurons or glial precursor cells. A-F, GFAP labeling (left), Cl sensor YFP fluorescence (center), and colocalization (right) within the SCN of GFAP-Cre+/Cl sensor+ animals. G-L, NFHC neuronal marker (left), Cl sensor YFP (center), and lack of colocalization (right) within the SCN. Scale bars are all $50 \mu \mathrm{m}$, images $\boldsymbol{A}-\boldsymbol{C}$ and $\mathbf{G}-\boldsymbol{I}$ were taken at $20 \times$ and images $\boldsymbol{D}-\boldsymbol{F}$ and $\boldsymbol{J}-\boldsymbol{L}$ were taken at $40 \times$.

present in the WIN solution. In contrast to the large percentage of cells in which WIN increased $\left[\mathrm{Ca}^{2+}\right] \mathrm{i}$, DMSO increased $\left[\mathrm{Ca}^{2+}\right] \mathrm{i}$ in only $16.4 \%$ of soma and $12.6 \%$ of non-soma regions (Fig. $3 A, E$ ). The average increase in response to WIN application was $0.287 \pm 0.028 \Delta \mathrm{F} / \mathrm{F}$, which was significantly higher than the DMSO average increase of $0.143 \pm 0.016 \Delta \mathrm{F} / \mathrm{F}$ (Table 3). WIN application produced small but significant decreases in $\left[\mathrm{Ca}^{2+}\right] \mathrm{i}(\mathrm{WIN}$ : $-0.134 \pm 0.010 \Delta \mathrm{F} / \mathrm{F}$ vs DMSO: $-0.105 \pm 0.003 \Delta \mathrm{F} / \mathrm{F})$. There was no significant difference between the soma and non-soma in the magnitude of the $\left[\mathrm{Ca}^{2+}\right] \mathrm{i}$ increases or decreases under WIN or DMSO. Those ROI that had variable responses, both exceeding the threshold for increased $\mathrm{Ca}^{2+}$ and decreased $\mathrm{Ca}^{2+}$ during the recording period, had low magnitude responses similar to DMSO indicating these responses may be normal, WIN- independent fluctuations of $\mathrm{Ca}^{2+}$ within the slice (Fig. $3 E, F)$. These data indicate that WIN increases astrocytic $\left[\mathrm{Ca}^{2+}\right] \mathrm{i}$, with low magnitude decreases or variable responses resembling vehicle control $\mathrm{Ca}^{2+}$ dynamics.

To determine whether this increase of astrocyte $\left[\mathrm{Ca}^{2+}\right] \mathrm{i}$ was driven by changes in neuronal activity, we performed the same experiment in the presence of TTX and CNQX to block synaptic transmission (Fig. 3C,G). Similar to the previous experiment, WIN application increased $\left[\mathrm{Ca}^{2+}\right] \mathrm{i}$ in $57.9 \%$ of the soma regions and $45.2 \%$ of the non-soma regions, indicating action potential firing by SCN neurons was not necessary for WIN to activate astrocyte $\left[\mathrm{Ca}^{2+}\right] \mathrm{i}$ pathways. Additionally, we found increased non-soma $\left[\mathrm{Ca}^{2+}\right] \mathrm{i}$ response in the presence of $T \mathrm{TX}$ and $\mathrm{CNQX}$ compared to the non-soma response to WIN (non-soma WIN: $0.279 \pm 0.030 \Delta \mathrm{F} / \mathrm{F}$, non-soma WIN + TTX/CNQX: 0.198 

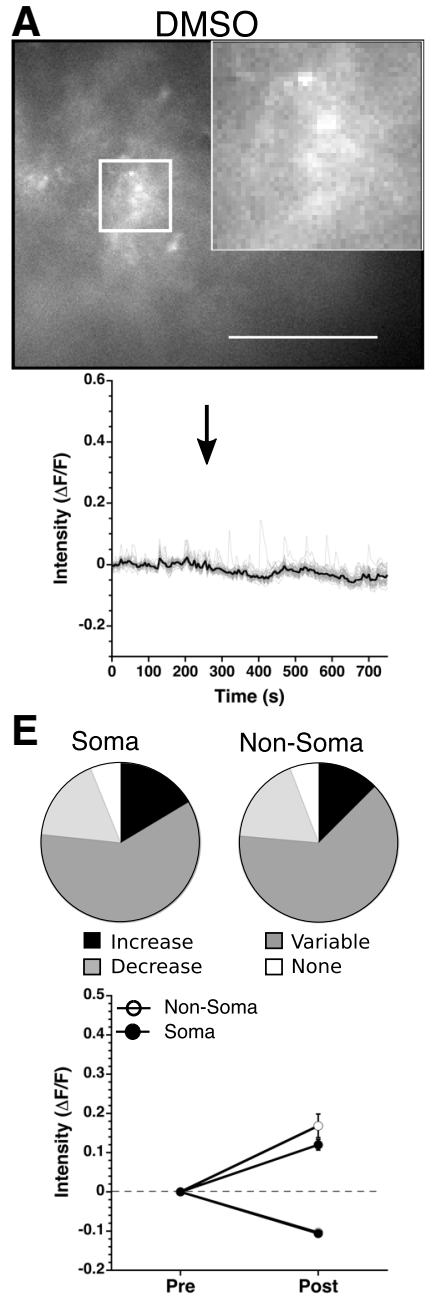
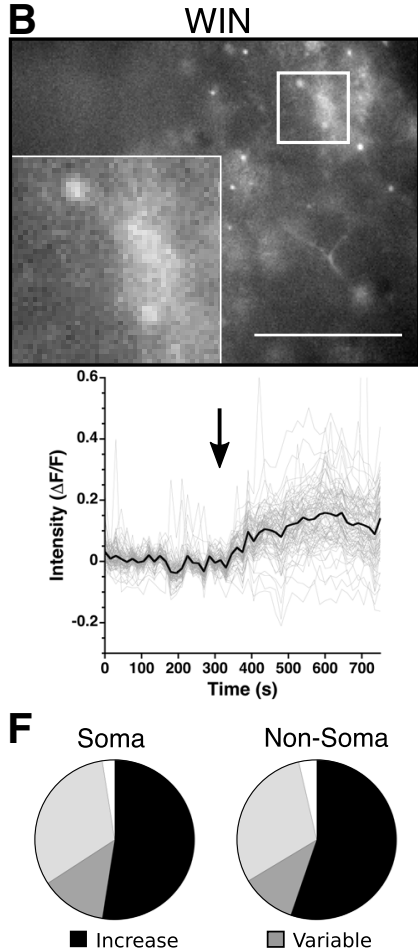

$\square$ Decrease
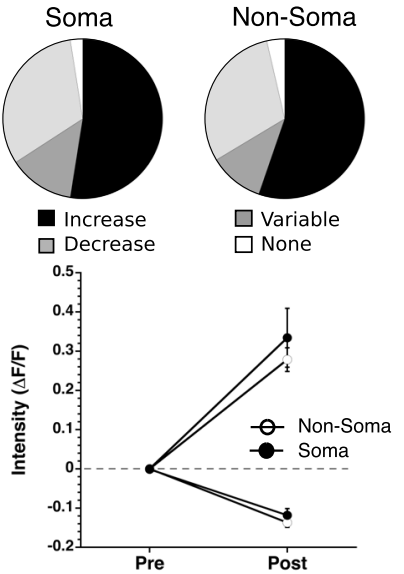
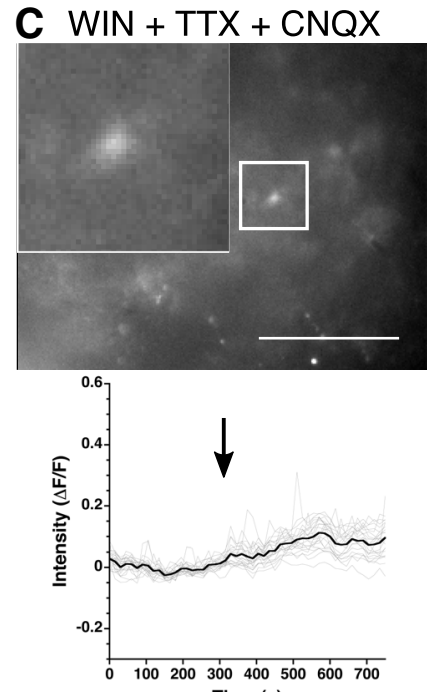

Time (s)

\section{G}

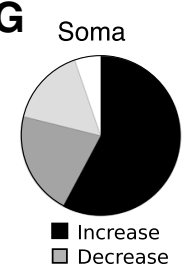

Non-Soma

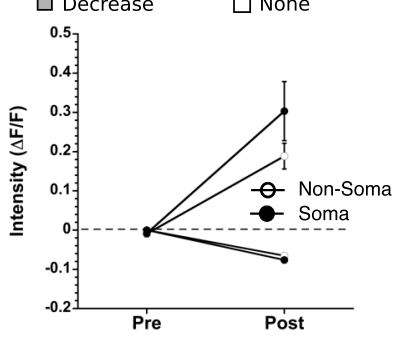

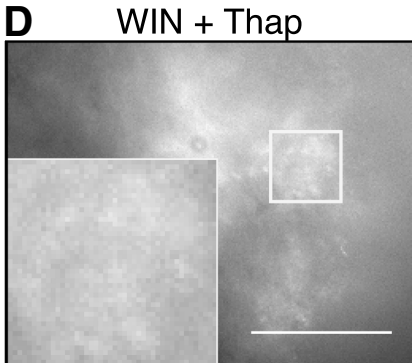

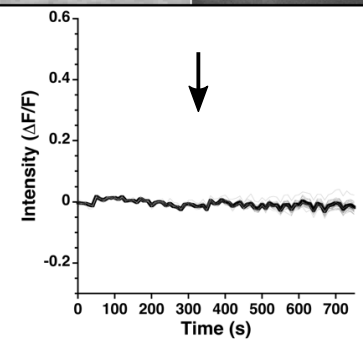

H
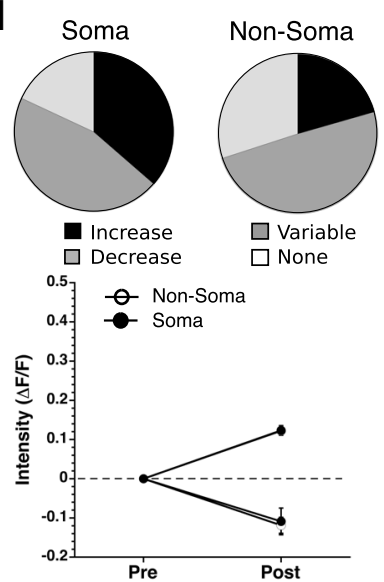

Figure 3. WIN activates an astrocytic $\mathrm{Ca}^{2+}$ signaling pathway. $\boldsymbol{A}-\boldsymbol{D}$, top, Representative GCaMP6 images from slices treated with DMSO $(0.01 \%)$, WIN $(3 \mu \mathrm{M})$, WIN $(3 \mu \mathrm{M})+\operatorname{TTX}(1 \mu \mathrm{M})+\mathrm{CNQX}(10 \mu \mathrm{M})$, and WIN $(3 \mu \mathrm{M})+$ thapsigargin $(1 \mu \mathrm{M}$; Thap). White scale bar is $50 \mu \mathrm{m}$, images taken at $40 \times$ and the inserts magnified 120X. Bottom, Representative traces showing the change in fluorescence from all regions measured (gray) and average response (black) from the slice depicted above. Black arrow indicates beginning of treatment. $\boldsymbol{E}-\boldsymbol{H}$, top, Pie charts depicting percentage of soma and non-soma regions across all slices responding with an increase (black), decrease (dark gray), variable response (light gray), or no response (white) to DMSO, WIN, WIN + TTX + CNQX, or WIN + Thap (left to right). Bottom, Cumulative average fluorescence increase during baseline and drug treatment for soma and non-soma regions across all slices.

$\pm 0.036 \Delta \mathrm{F} / \mathrm{F} ;$ Table 3). There were no significant differences in the soma responses to WIN. This indicates that inhibition of neuronal firing may alter a neuronal signal or signals, such as endocannabinoids, that regulate the $\left[\mathrm{Ca}^{2+}\right]$ i in non-soma regions of SCN astrocytes (MetnaLaurent and Marsicano, 2015). Of the cells that showed a decreased $\left[\mathrm{Ca}^{2+}\right] \mathrm{i}$, there were no significant differences in the amplitude of the $\mathrm{Ca}^{2+}$ responses between soma and non-soma regions, regardless of the presence of TTX+CNQX. In summary, WIN increases $\left[\mathrm{Ca}^{2+}\right]$ independent of neuronal firing, but neuronal signaling may modulate the magnitude of non-somatic $\mathrm{Ca}^{2+}$ responses.

To test the hypothesis that WIN-induced $\left[\mathrm{Ca}^{2+}\right] \mathrm{i}$ increases are dependent on intracellular $\mathrm{Ca}^{2+}$ stores, we used thapsigargin, a non-competitive inhibitor of the sarco/endoplasmic reticulum $\mathrm{Ca}^{2+}$ ATPase, to deplete intracellular $\mathrm{Ca}^{2+}$ stores (Fig. 3D,H). Thapsigargin (1 $\left.\mu \mathrm{M}\right)$ increased $\left[\mathrm{Ca}^{2+}\right]$ i by $380.4 \pm 165.5 \%$ from pre-treatment levels, with $\mathrm{Ca}^{2+}$ levels dropping off significantly after the maximum as internal stores were depleted. WIN $(3 \mu \mathrm{M})$ was applied after the $\left[\mathrm{Ca}^{2+}\right]$ i reached a steady state value for at least $300 \mathrm{~s}$. Because thapsigargin depletes intracellular $\mathrm{Ca}^{2+}$ stores, and the intensity of the GCaMP6 signal is dependent on $\left[\mathrm{Ca}^{2+}\right] \mathrm{i}$, fewer somas were identifiable after $\mathrm{Ca}^{2+}$ depletion (before thapsigargin treatment: 35 visible somas, after: 11 visible somas). Thapsigargin treatment reduced the number and magnitude of WIN-induced $\left[\mathrm{Ca}^{2+}\right] \mathrm{i}$ increases indicating that WIN is activating $\mathrm{Ca}^{2+}$ release from intracellular stores. Of the 11 soma regions, only 4 showed an increase. Similarly, only 20 of the 97 non-soma regions showed an increase (Fig. $3 H$ ). The magnitude of these responses were smaller than responses without thapsigargin, although only the non-soma group, where the sample size was larger, was statistically significant 
A

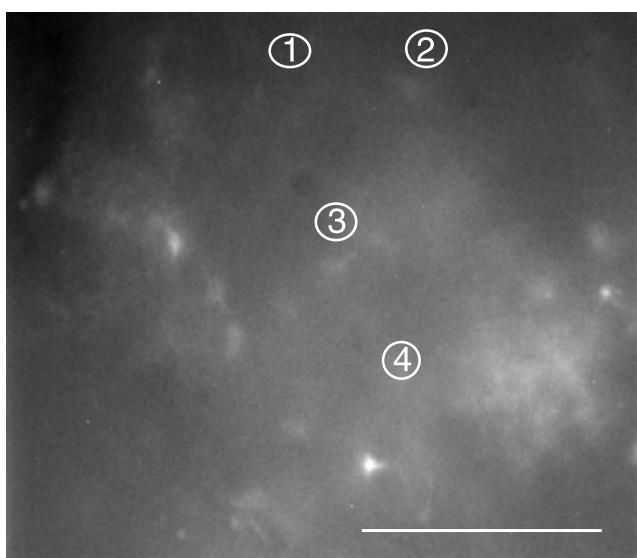

B

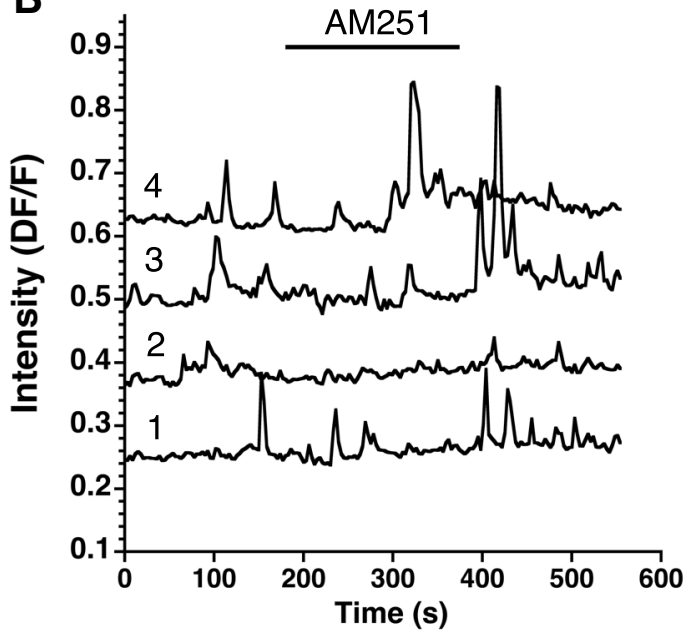

C

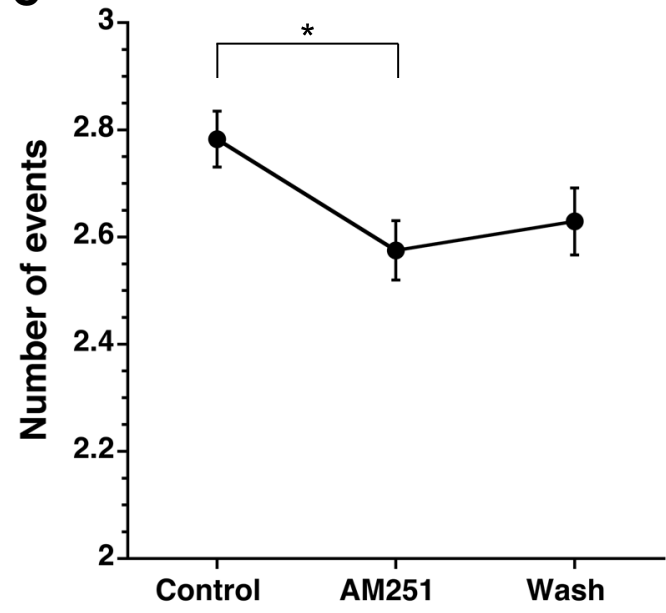

D

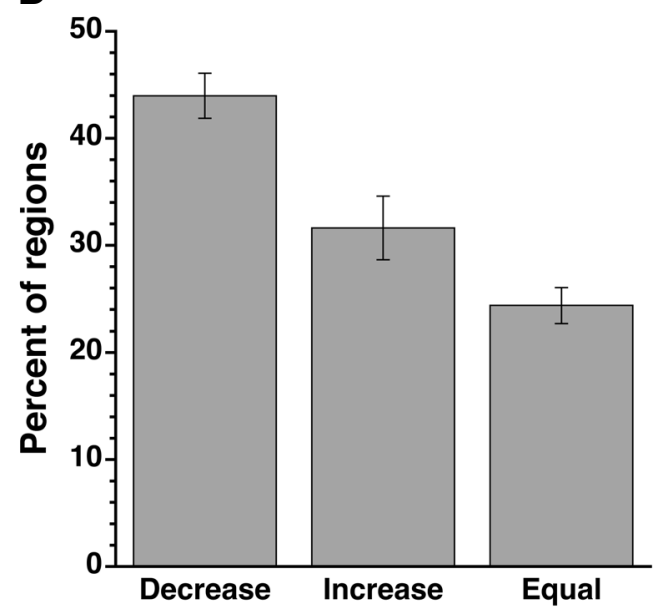

E
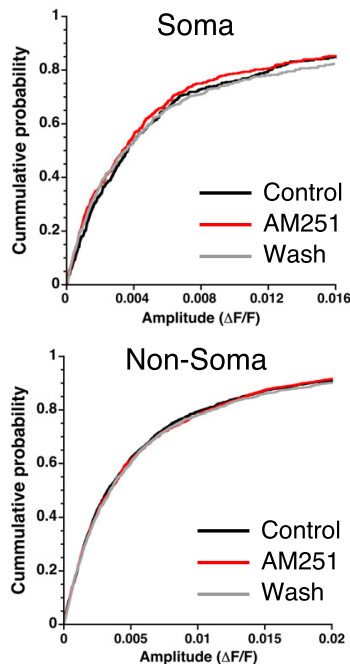

Figure 4. Blockade of CB1R alters the frequency of spontaneous astrocytic $\mathrm{Ca}^{2+}$ events. A, Representative GCaMP6 image. White scale bar is $50 \mu \mathrm{m}$, image taken at $40 \times$. White, numbered ellipses are the ROls plotted in $\boldsymbol{B}$. $\boldsymbol{B}$, Representative traces of intensity 180 $\mathrm{s}$ before, during, and after AM251 treatment (indicated by black bar). Numbers 1-4 correspond to numbered regions in $\boldsymbol{A}$. Note that the event examples were picked to reflect the varying responses to AM251 with traces 2 and 3 showing a clear reduction in frequency. $\boldsymbol{C}$, Average event numbers across all experiments of regions before, during, and after AM251 treatment depicted as mean \pm SEM ( $* p$ $<0.05$, Friedman test). $\boldsymbol{D}$, Average percentage of regions responding with a decrease, increase, or no change on treatment with AM251 across all experiments (mean \pm SEM). $\boldsymbol{E}$, Cumulative probability curves of amplitude for both soma (top) and non-soma (bottom) regions before, during, and after treatment with AM251.

(non-soma: $0.122 \pm 0.011 \Delta \mathrm{F} / \mathrm{F}$, soma: $0.123 \pm 0.012 \Delta \mathrm{F} / \mathrm{F}$; Table 3). These data demonstrate that activation of $\mathrm{CB} 1$ receptors by WIN activates an intracellular $\mathrm{Ca}^{2+}$ signaling pathway in SCN astrocytes.

\section{Neurons utilize endocannabinoid signaling to alter astrocyte function}

We demonstrated that WIN-induced CB1R activation increased astrocytic $\left[\mathrm{Ca}^{2+}\right] \mathrm{i}$ (Fig. 3). However, agonistinduced activation of CB1R does not address endogenous, spontaneous $\mathrm{Ca}^{2+}$ signaling in astrocytes. Spontaneous $\mathrm{Ca}^{2+}$ events change both local and network wide intracellular signaling within and across astrocytes, disruption of which has been linked to neuropathology (Shigetomi et al., 2016). We determined the role of endogenous cannabinoid signaling in regulating these spontaneous
$\mathrm{Ca}^{2+}$ events within GCaMP6 expressing astrocytes by applying AM251 (Fig. 4). Total event numbers were summed for the 3 min prior, 3 min during, and 3 min after AM251 treatment. AM251, reduced the frequency of $\left[\mathrm{Ca}^{2+}\right] \mathrm{i}$ events in $42.9 \%$ of somas. In non-soma regions $\mathrm{AM} 251$ reduced the number of spontaneous $\mathrm{Ca}^{2+}$ events in $44.1 \%$ of regions (Fig. 4D). We found no difference in event amplitude between soma and non-soma regions before, during, or after AM251 treatment (Fig. 4E; Table 4).

Both soma and non-soma regions responded similarly in the regions in which AM251 decreased the spontaneous $\mathrm{Ca}^{2+}$ event frequency, with the number of events decreasing during treatment and a significant recovery during 3 min of washout (Fig. 4C; Table 4). Similarly, soma and non-soma regions with an increased frequency of $\mathrm{Ca}^{2+}$ events saw a return to baseline after treatment 
Table 4. Statistics for the data shown in Figure 4

\begin{tabular}{|c|c|c|c|}
\hline Figure & Statistical test & Statistics output & $N$ \\
\hline Fig. $3 D, H$ & & & $\begin{array}{l}\text { Thapsigargin + WIN: } 3 \text { mice, } 4 \text { slices, } 11 \\
\text { soma (s), } 97 \text { non-soma (ns) }\end{array}$ \\
\hline $\begin{array}{l}\text { Increase magnitude: treatment (WIN/ Thap + } \\
\text { WIN }) \times \mathrm{ROI}(\mathrm{s} / \mathrm{ns})\end{array}$ & Kruskal-Wallis & $\mathrm{H}(3)=14.685, p=0.002$ & \\
\hline Fig. 4 & & & AM251: 4 mice, 8 slices, 175 s, 818 ns \\
\hline $\begin{array}{l}\text { Decreased events in s: event number } \times \\
\text { time (base, AM251, wash) }\end{array}$ & Friedman & $\begin{array}{l}\chi^{2}(2)=83.089 \\
p<0.0001\end{array}$ & \\
\hline Base to AM251 & Wilcoxon signed-rank & $Z=-7.621, p<0.0001$ & \\
\hline Base to wash & Wilcoxon signed-rank & $Z=-3.732, p<0.0001$ & \\
\hline AM251 to wash & Wilcoxon signed-rank & $Z=-2.275, p=0.001$ & \\
\hline $\begin{array}{l}\text { Decreased events in ns: event number } \times \\
\text { time (base, AM251, wash) }\end{array}$ & Friedman & $X^{2}(2)=394.339, p<0.0001$ & \\
\hline Base to AM251 & Wilcoxon signed-rank & $Z=-16.763, p<0.0001$ & \\
\hline Base to wash & Wilcoxon signed-rank & $Z=-8.882, p<0.0001$ & \\
\hline AM251 to wash & Wilcoxon signed-rank & $Z=-7.578, p<0.0001$ & \\
\hline $\begin{array}{l}\text { Increased events in s: event number } \times \\
\text { time (base, AM251, wash) }\end{array}$ & Friedman & $\chi^{2}(2)=54.926, p=0.000$ & \\
\hline Base to AM251 & Wilcoxon signed-rank & $Z=-6.740, p<0.0001$ & \\
\hline Base to wash & Wilcoxon signed-rank & $Z=-3.090, p=0.002$ & \\
\hline AM251 to wash & Wilcoxon signed-rank & $Z=-2.953, p=0.003$ & \\
\hline $\begin{array}{l}\text { Increased events in ns: event number } \times \\
\text { time (base, AM251, wash) }\end{array}$ & Friedman & $X^{2}(2)=302.035, p=0.000$ & \\
\hline Base to AM251 & Wilcoxon signed-rank & $Z=-14.338, p<0.0005$ & \\
\hline Base to wash & Wilcoxon signed-rank & $Z=-5.648, p<0.0005$ & \\
\hline AM251 to wash & Wilcoxon signed-rank & $Z=-9.564, p<0.0005$ & \\
\hline
\end{tabular}

(soma: base: $1.7 \pm 0.1$ events, treat: $3.5 \pm 0.2$ events, wash: $2.7 \pm 0.2$ events; non-soma: base: $2.0 \pm 0.1$ events, treat: $4.0 \pm 0.1$ events, wash: $2.7 \pm 0.1$ events; Table 4) indicating that AM251 blockade of endocannabinoid signaling is transient and washes out. Inhibition of the spontaneous $\mathrm{Ca}^{2+}$ signals demonstrates the presence of endogenous cannabinoid signaling in the SCN slice.

Endocannabinoid signaling acts as a retrograde signal from a postsynaptic neuron to presynaptic axon terminals, and our model suggests that in the SCN astrocytes are necessary for this process, responding to a postsynaptic neuronal release of endocannabinoids with a $\mathrm{Ca}^{2+}$ signaling event. To test this hypothesis, neurons were recorded in whole cell patch clamp mode and voltageclamped at $-60 \mathrm{mV}$, then depolarized (10 pulses from -80 to $+20 \mathrm{mV}, 100 \mathrm{~ms}$ duration, $5 \mathrm{~Hz}$ ) while $\mathrm{Ca}^{2+}$ events were recorded from GCaMP6 expressing astrocytes (Fig. 5). The number of $\mathrm{Ca}^{2+}$ events $30 \mathrm{~s}$ before and after neuronal depolarization were compared before, during and after AM251 application to determine whether depolarization increased $\mathrm{Ca}^{2+}$ events in a CB1R-dependent manner. Before cannabinoid receptor blockade, the depolarization protocol significantly increased the number of spontaneous $\mathrm{Ca}^{2+}$ events (pre-depol: $1.47 \pm 0.08$ events, post-depol: $2.10 \pm 0.07$ statistics in Table 4). AM251 treatment prevented the depolarization-induced increase in $\mathrm{Ca}^{2+}$ event frequency (pre-depol: $1.18 \pm 0.07$ events, post-depol: $1.33 \pm 0.07$ events), an effect that recovered after 3 min of washout (pre-depol: $1.04 \pm 0.06$ events, post-depol: $1.72 \pm 0.06$ events; Fig. $5 C, D)$. There were no differences in event amplitude distributions among any groups (Fig. 5E). These experiments demonstrated that depolarization of a postsynaptic neuron activated $\mathrm{Ca}^{2+}$ signals in astrocytes that were dependent on endocannabinoid signaling.

\section{Adenosine signaling is necessary for WIN response}

Cannabinoid signaling, both via endocannabinoids and the synthetic cannabinoid WIN, activated a $\mathrm{Ca}^{2+}$ response in astrocytes, and WIN can decrease release of GABA in SCN neurons in an astrocyte-dependent manner. Next, we wanted to identify the mechanism by which astrocytes decrease presynaptic GABA release. In other areas of the brain, astrocytes release glutamate that alters presynaptic function by activating metabotropic glutamate receptors (Liu et al., 2004; Perea and Araque, 2007; Rusakov, 2015). We demonstrated that this is not the case in the SCN by using ACPTII, a competitive metabotropic receptor inhibitor. ACPTII alone did not significantly alter mGPSC frequency or amplitude. However, on addition of WIN the mGPSC frequency significantly decreased (ACPTII+WIN: $-19.2 \pm 4.5 \%$, statistics in Table 5) without significantly altering amplitude, indicating metabotropic glutamate receptors are not required for cannabinoidinduced astrocyte-mediated presynaptic changes (Fig. 6A; Table 5).

Astrocytes can release ATP that can then be converted to adenosine and activate adenosine receptors (Ben Achour and Pascual, 2012; Losi et al., 2014; Yamashiro et al., 2017; Svobodova et al., 2018). CGS15943, a potent $\mathrm{A} 1$ and $\mathrm{A} 2 \mathrm{~A}$ adenosine receptor antagonist, was used to test the hypothesis that adenosine receptor signaling is necessary for the effects of WIN in the SCN (Fig. 6B; Table 5). Initially, CGS15943 (50 $\mu \mathrm{M})$ alone did not significantly alter mGPSC frequency (Tables 1, 5), and had negligible impact on mGPSC amplitude (CGS15943: 1.3 \pm 1.8\%; Tables 2, 5). More interestingly, WIN had no effect on mGPSC frequency with CGS15943 in the bath (CGS15943+WIN: $-0.5 \pm 0.5 \%$ ). Once again, the mGPSC amplitude showed very little change (CGS15943+WIN: -6.0 \pm 3.0\%). Next, because CGS15943 activates multiple adenosine receptors, we used the adenosine-1 receptor (A1R)-specific 
A
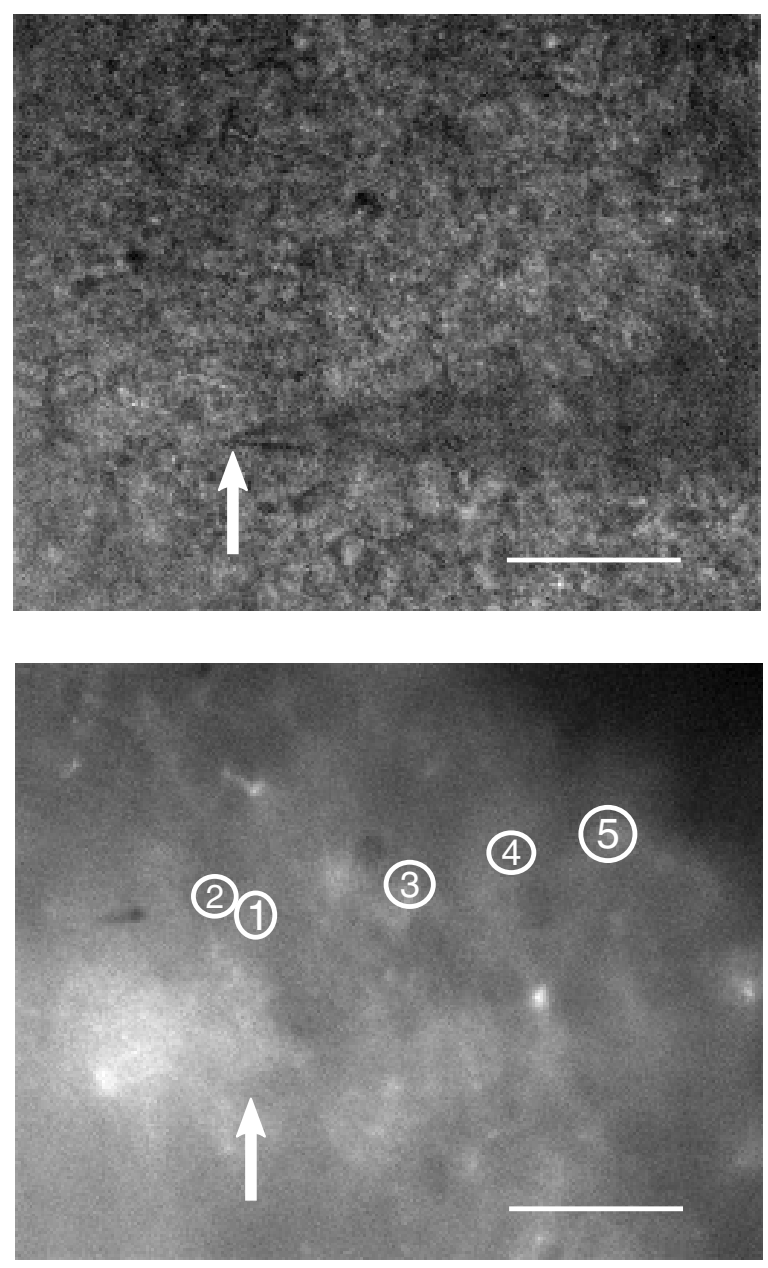

B
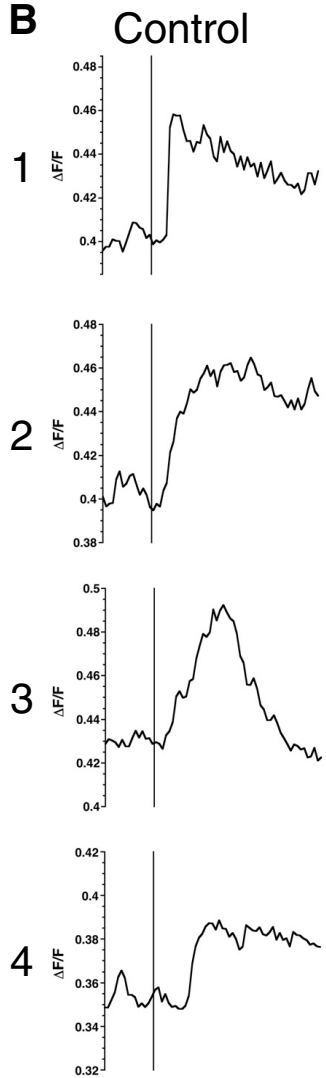

5

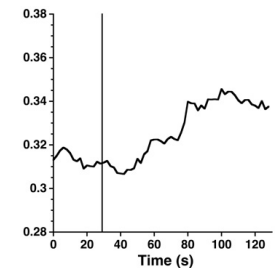

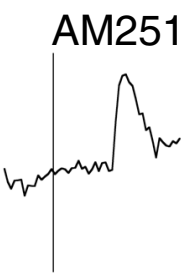
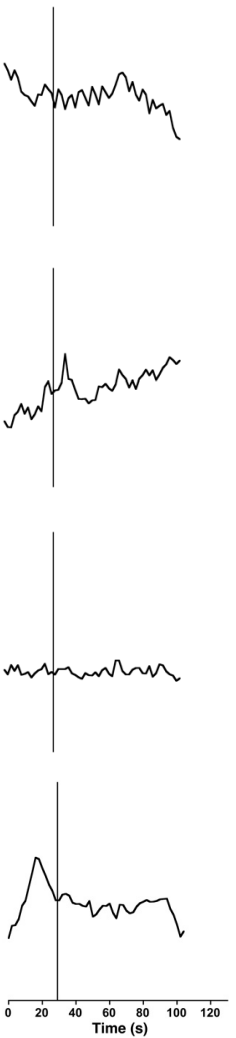

C

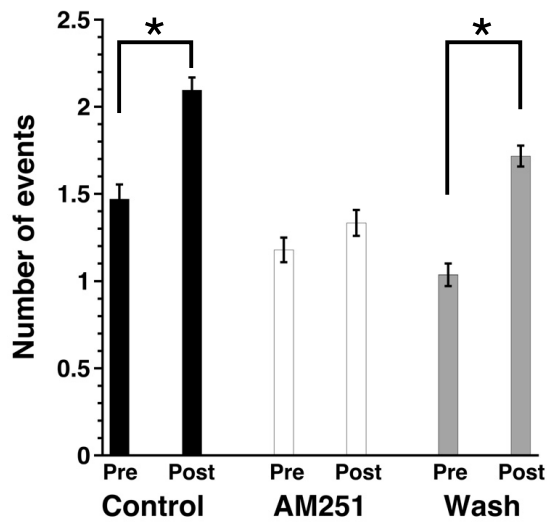

D

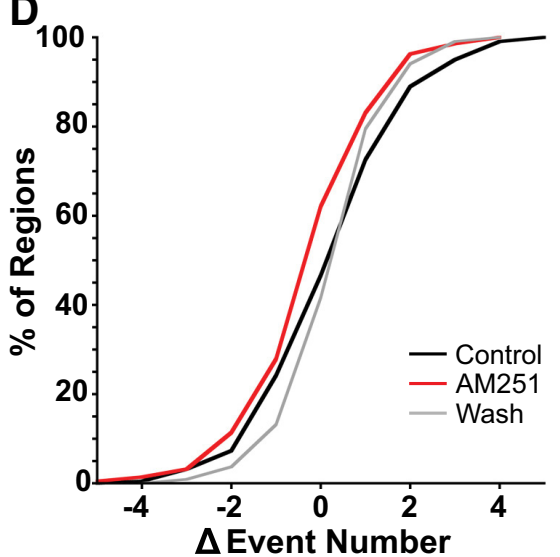

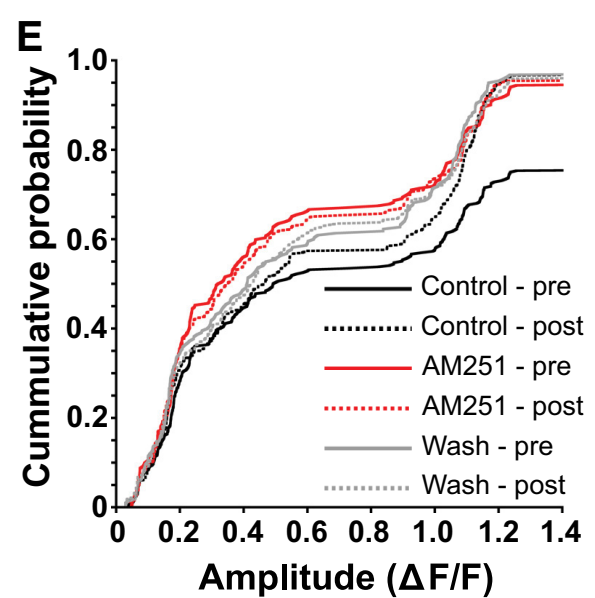

Figure 5. Neurons utilize endocannabinoid signaling to activate astrocyte $\mathrm{Ca}^{2+}$ signaling pathways. $\boldsymbol{A}$, Representative bright field (top) and GCaMP6 (bottom) images from a single slice. White scale bar is $50 \mu \mathrm{m}$, images taken at $40 \times$. White arrow indicates the placement of the microelectrode tip. Numbered ellipses correspond to locations of traces in $\boldsymbol{B}$. $\boldsymbol{B}$, Representative intensity changes from the regions marked in $\boldsymbol{A}$ before and after depolarization of an SCN neuron (indicated by black bar) before (left) and during (right) AM251 (5 $\mu \mathrm{M})$ treatment. C, Average number of events pre- and post-depolarization, before, during, and after treatment with AM251 across all experiments (mean $\pm \mathrm{SEM}, * p<0.05$, Friedman test). $\boldsymbol{D}$, Cumulative percentage of regions per change in event number from depolarization, before, during, and after AM251. E. Boxplot of event amplitudes pre- and post-depolarization, before, during, and after treatment with AM251. 
Table 5. Statistics for the data shown in Figures 5-Figures 8

\begin{tabular}{|c|c|c|c|}
\hline Figure & Statistical test & Statistics output & $N$ \\
\hline Fig. 5 & & & $\begin{array}{l}\text { Depol + AM251: } 9 \text { neurons, } 4 \text { mice, } 225 \text { ROls } \\
\text { [soma (s) and non-soma (ns)] }\end{array}$ \\
\hline $\begin{array}{l}\text { Change in events: events (pre/post depol) } \times \\
\text { time (base, AM251, wash) }\end{array}$ & Friedman & $\chi^{2}(5)=155.838, p<0.0005$ & \\
\hline Pre to post base & Wilcoxon signed-rank & $Z=-5.418, p<0.0005$ & \\
\hline Pre to post AM251 & Wilcoxon signed-rank & $Z=-7.401, p<0.0005$ & \\
\hline Pre to post Wash & Wilcoxon signed-rank & $Z=-1.755, p=0.079$ & \\
\hline Fig. $6 A$ & & & ACPTII: 9 neurons, 3 mice \\
\hline mGPSC frequency: DMSO $\times$ ACPTII & ANOVA & $F_{(1,28)}=0.746, p=0.395$ & \\
\hline mGPSC amplitude: DMSO × ACPTII & ANOVA & $F_{(1,28)}=2.135, p=0.155$ & \\
\hline mGPSC frequency: ACPTII $\times$ ACPTII + WIN & ANOVA & $F_{(1,8)}=19.527, p=0.002$ & \\
\hline mGPSC amplitude: ACPTII $\times$ ACPTII + WIN & ANOVA & $F_{(1,8)}=3.206, p=0.067$ & \\
\hline Fig. $6 B$ & & & CGS: 8 neurons, 3 mice \\
\hline mGPSC frequency: DMSO × CGS15943 (CGS) & ANOVA & $F_{(1,28)}=1.539, p=0.225$ & \\
\hline mGPSC frequency: CGS $\times$ CGS + WIN & ANOVA & $F_{(1,7)}=1.754, p=0.227$ & \\
\hline Fig. $6 \mathrm{C}$ & & & DPCPX: 12 neurons, 4 mice \\
\hline mGPSC frequency: DMSO $\times$ DPCPX & ANOVA & $F_{(1,31)}=0.03, p=0.863$ & \\
\hline mGPSC amplitude: DMSO $\times$ DPCPX & ANOVA & $F_{(1,31)}=0.032, p=0.858$ & \\
\hline mGPSC frequency: DPCPX $\times$ DPCPX + WIN & ANOVA & $F_{(1,11)}=0.007, p=0.935$ & \\
\hline mGPSC amplitude: DPCPX $\times$ DPCPX + WIN & ANOVA & $F_{(1,11)}=2.353, p=0.153$ & \\
\hline Fig. 7 & & & Adenosine: 15 neurons, 4 mice \\
\hline mGPSC frequency: DMSO $\times$ adenosine & ANOVA & $F_{(1,32)}=4.144, p=0.05$ & \\
\hline mGPSC amplitude: DMSO $\times$ adenosine & ANOVA & $F_{(1,32)}=4.041, p=0.053$ & \\
\hline Fig. 8 & & & CNO: 7 slices, 54 s, 265 ns \\
\hline $\begin{array}{l}\text { Increase magnitude CNO: } \\
\mathrm{s} \times \mathrm{ns}\end{array}$ & Mann-Whitney $U$ & $U=2667, p=0.95$ & \\
\hline $\begin{array}{l}\text { Increase magnitude: treatment }(\mathrm{CNO} / \text { Thap }+ \\
\mathrm{CNO}) \times \mathrm{ROI}(\mathrm{s} / \mathrm{ns})\end{array}$ & Kruskal-Wallis & $H(3)=15.400, p=0.001$ & Thap + CNO: 3 mice, $7 \mathrm{~s}, 64$ ns \\
\hline Increase magnitude ns: $\mathrm{CNO} \times$ Thap $+\mathrm{CNO}$ & Median post hoc & $p=0.022$ & \\
\hline
\end{tabular}

antagonist DPCPX to determine whether A1R, specifically, mediated the response to WIN. DPCPX $(0.2 \mu \mathrm{M})$ alone altered neither the mGPSC frequency nor amplitude. WIN (3 $\mu \mathrm{M})$ application in the presence of DPCPX $(0.2 \mu \mathrm{M})$, did not alter either the frequency (DPCPX+WIN: $-6.5 \pm 6.1 \%$ ) nor amplitude (Fig. $6 C$; Tables 2, 5), indicating that the presynaptic effects of cannabinoids are due to $A 1 R$ activation.

If the effects of cannabinoids are dependent on astrocyte function and adenosine receptor activation, then adenosine should have similar effects as WIN on mGPSC frequency. Indeed, adenosine $(100 \mu \mathrm{M})$ causes a significant reduction of mGPSC frequency compared to controls (adenosine: $-20.5 \pm 5.3 \%$ ) but does not significantly alter mGPSC amplitude (Fig. 7; Tables 1, 2, 5).

\section{Activation of a $\mathrm{Ca}^{2+}$ response in astrocytes changes neuronal function in the SCN}

After demonstrating that cannabinoids increase $\left[\mathrm{Ca}^{2+}\right] \mathrm{i}$ in SCN astrocytes and release adenosine, we next asked whether activation of astrocytic $\mathrm{Ca}^{2+}$ signaling pathways could cause an adenosine-dependent decrease in mGPSC frequency independent of cannabinoid signaling. Designer receptors exclusively activated by designer drugs (DREADDs) are mutated muscarinic acetylcholine receptors that respond only to $\mathrm{CNO}$, a metabolite of acetylcholine not traditionally found in mice, allowing for cell type specific expression and activation of G-protein signaling (Rogan and Roth, 2011). We expressed Gq coupled DREADDs together with GCaMP6 in GFAP-Cre+ astrocytes (Fig. 8). Application of the DREADD agonist CNO increased $\left[\mathrm{Ca}^{2+}\right] \mathrm{i}$ in $55.6 \%$ of soma regions (13\% no response, $16.7 \%$ decrease, and $14.8 \%$ variable), and produced a similar response in non-soma regions $(56.2 \%$ increase, $9.4 \%$ no response, $20.8 \%$ decrease, and $13.6 \%$ variable, statistics in Table 5; Fig. $8 \mathrm{C}$ ). The magnitude of the $\left[\mathrm{Ca}^{2+}\right] \mathrm{i}$ increases was not significantly different between soma and non-soma regions (soma: $0.402 \pm$ $0.0828 \Delta \mathrm{F} / \mathrm{F}$, non-soma: $0.269 \pm 0.018 \Delta \mathrm{F} / \mathrm{F}$; Fig. $8 D$ ). After depleting $\mathrm{Ca}^{2+}$ stores with thapsigargin $(1 \mu \mathrm{M})$, the magnitude of the $\mathrm{CNO}$-induced $\mathrm{Ca}^{2+}$ responses in the soma and non-soma regions was reduced (soma: $0.126 \pm$ $0.007 \Delta F / F$, non-soma: $0.169 \pm 0.038 \Delta F / F)$. Similar to the $\mathrm{WIN}+$ thapsigargin experiment, this effect was significant in the non-soma groups but not the soma groups due to smaller sample size of cell body regions after $\mathrm{Ca}^{2+}$ depletion with thapsigargin (Table 5). Application of CNO in the absence of Gq DREADD expression had no effect on the mGPSC amplitude (CNO without DREADD: $-4.8 \pm$ $1.4 \%$ ) or frequency (CNO without DREADD: $-10.2 \pm$ $2.1 \%$ ) compared to DMSO controls (Table 6). Because CNO did not alter the mGPSC frequency or amplitude when applied without the Gq DREADD, and DMSO does not significantly increase GCaMP6 signaling (Fig. 3) we did not investigate the effects of CNO $(10 \mu \mathrm{M})$ on GCaMP6 signaling in the absence of DREADD expression.

We hypothesized that activating a $\mathrm{Ca}^{2+}$ response in astrocytes would decrease presynaptic GABA release in the SCN because the Gq DREADD activation increased $\left[\mathrm{Ca}^{2+}\right]$ i similar to that induced by WIN. Indeed, mGPSC frequency was significantly reduced in CNO treated groups compared to controls (CNO: $-18 \pm 4 \%$ ) while the amplitude showed no difference (Fig. 9A-C; Tables 4-Tables 6). The reduction of mGPSC frequency by WIN was eliminated by blocking A1Rs with DPCPX (DPCPX+CNO: -6.1 $\pm 6.5 \%$; Table 6) while the mGPSC amplitudes were not 

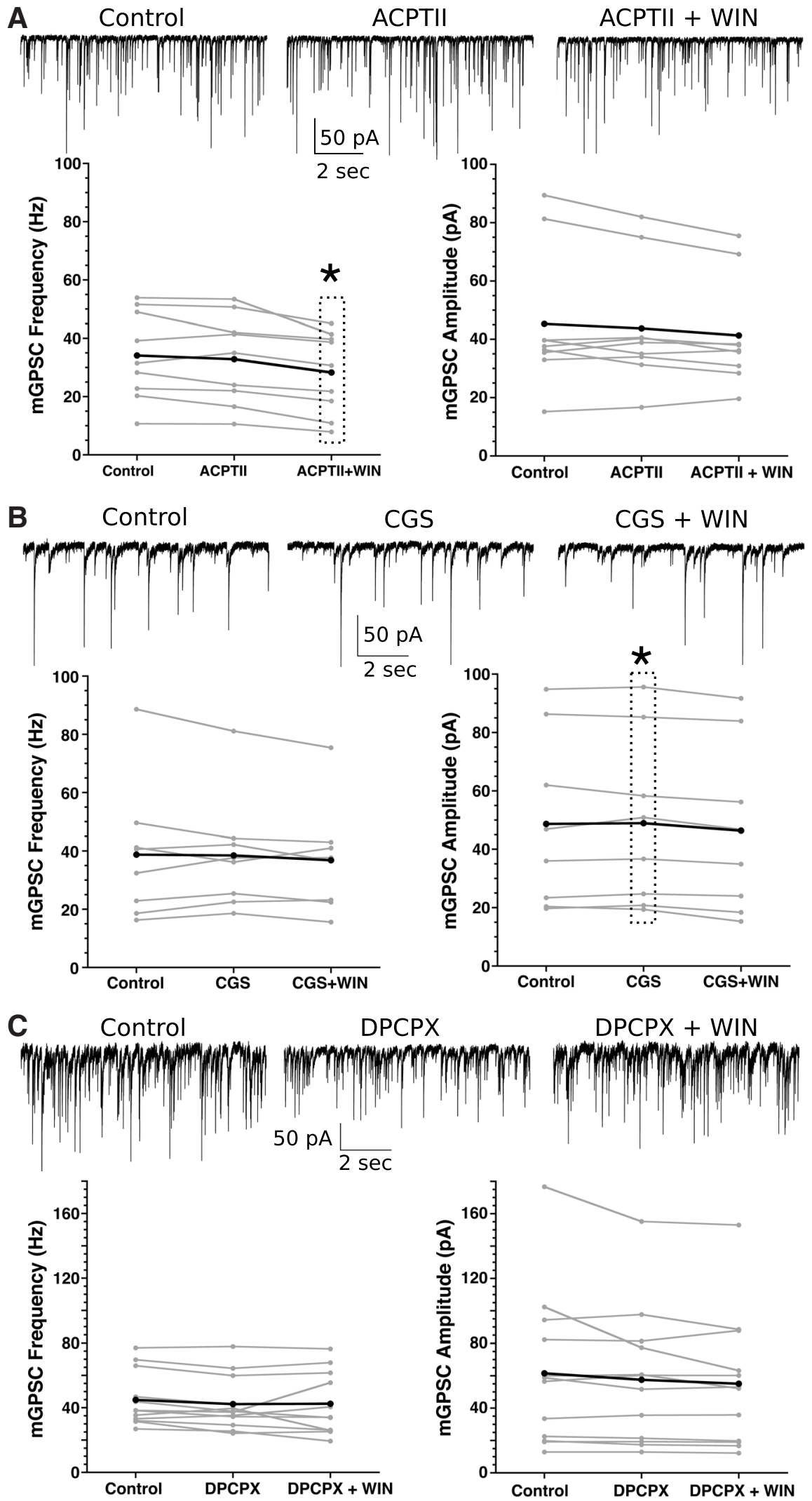

Figure 6. Adenosine signaling is necessary for WIN-induced mGPSC frequency changes. $\boldsymbol{A}$, top, Representative traces pretreatment (left), with ACPTII (middle), and with ACPTII+WIN (right) from an individual neuron. Bottom, Individual cell mGPSC frequency (left) and amplitude (right) before, during application of ACPTII $(200 \mu \mathrm{M})$, and both ACPTII $(200 \mu \mathrm{M})+$ WIN $(3 \mu \mathrm{M} ; * p<0.05$, repeated measures analysis). $\boldsymbol{B}$, top, Representative traces pretreatment (left), with CGS15943 (CGS, middle), and with CGS +WIN (right) from 
continued

an individual neuron. Bottom, Individual cell mGPSC frequency and amplitude pretreatment, with CGS (50 $\mu \mathrm{M})$, and both CGS (50 $\mu \mathrm{M})$ and WIN $(3 \mu \mathrm{M})$. C, top, Representative traces (left) pretreatment, with DPCPX (middle), and with DPCPX + WIN (right) from an individual neuron. Bottom, Individual cell and mean mGPSC frequency (left) and amplitude (right) pretreatment, with DPCPX (0.2 $\mu \mathrm{M})$, and both DPCPX $(0.2 \mu \mathrm{M})$ and WIN $(3 \mu \mathrm{M})$. For all frequency and amplitude plots, gray lines indicate individual neuron responses, black lines represent group averages.

affected (Fig. 9D-F; Tables 1, 6), indicating that like cannabinoid signaling, activation of a $\mathrm{Ca}^{2+}$ response in astrocytes initiates a presynaptic inhibition of GABA release dependent on adenosine receptor signaling.

\section{Both cannabinoid and adenosine signaling change circadian clock timing}

Cannabinoid signaling alters both astrocytic and neuronal function in the SCN. Cannabinoids also block lightinduced phase shifts, but had no effect on clock timing at night (Sanford et al., 2008; Acuna-Goycolea et al., 2010). Experiments were performed to determine whether CB1R activation can phase shift the molecular clock when administered during the day using the PERIOD2::LUCIFERASE mouse model (Yoo et al., 2004). We applied WIN $(3 \mu \mathrm{m})$ for $1 \mathrm{~h}$ to PER2::LUC SCN cultures during the early day (CT1-CT6). WIN significantly phase advanced PER2::LUC rhythms compared to DMSO (0.01\%) vehicletreated controls (WIN: $2.5 \pm 1.3 \mathrm{~h}$, vehicle: $0.2 \pm 0.1 \mathrm{~h}$ ), indicating that cannabinoids can indeed influence circadian timing (Fig. 10; Table 6). We tested the dependency of this phase shift on A1R signaling. We find the A1R antagonist DPCPX does not induce a phase shift when applied for $1 \mathrm{~h}$ during the day (DPCPX: $0.3 \pm 0.2 \mathrm{~h}$ ), and co-treatment of WIN and DPCPX does not produce the phase advance seen with WIN alone (DPCPX+WIN: $0.1 \pm$ $0.2 \mathrm{~h}$; Fig. 10B; Table 6). There was no change in period length between pre- and post-treatment under any treatment paradigm (pre-treatment period: $25.9 \pm 0.1 \mathrm{~h}$, post- treatment period: $25.8 \pm 0.2 \mathrm{~h}$; Table 6). These data indicate that cannabinoid signaling in the clock center of the brain can alter circadian timing in an A1R-dependent manner. Since the WIN-induced decrease in MGPSC frequency and phase advance of PER2::LUC rhythms are dependent on A1R activation, we hypothesized that adenosine would have similar phase shifting effects as WIN. Indeed, application of adenosine $(100 \mu \mathrm{M})$ during the early day for $1 \mathrm{~h}$ significantly phase advanced the PER2:: LUC rhythms compared to vehicle-treated controls (mean \pm SEM, adenosine: $3.7 \pm 1.7 \mathrm{~h}$, vehicle: $0.5 \pm 0.3 \mathrm{~h}$ (Fig. 10C,D; Table 6). Similar to the WIN experiments, there was no significant effect of adenosine treatment on period length (Table 6), although there was a significant shortening of period after treatment (pre-treatment period: $27.1 \pm$ $0.4 \mathrm{~h}$, post-treatment period: $25.5 \pm 0.3 \mathrm{~h}$ ) which may have been due to a different vehicle (water instead of DMSO).

\section{Discussion}

In the SCN, postsynaptic neurons recruit astrocytes via endocannabinoid signaling to modulate presynaptic GABA release. Activation of CB1Rs with the cannabinoid agonist WIN decreases the frequency but not the amplitude of mGPSCs in the SCN, consistent with a reduction in GABA release. This effect is dependent on astrocyte function, and A1R activation. WIN also induces an astrocytic $\mathrm{Ca}^{2+}$ signaling cascade. Mimicking this increased $\mathrm{Ca}^{2+}$ signal in astrocytes using DREADD technology
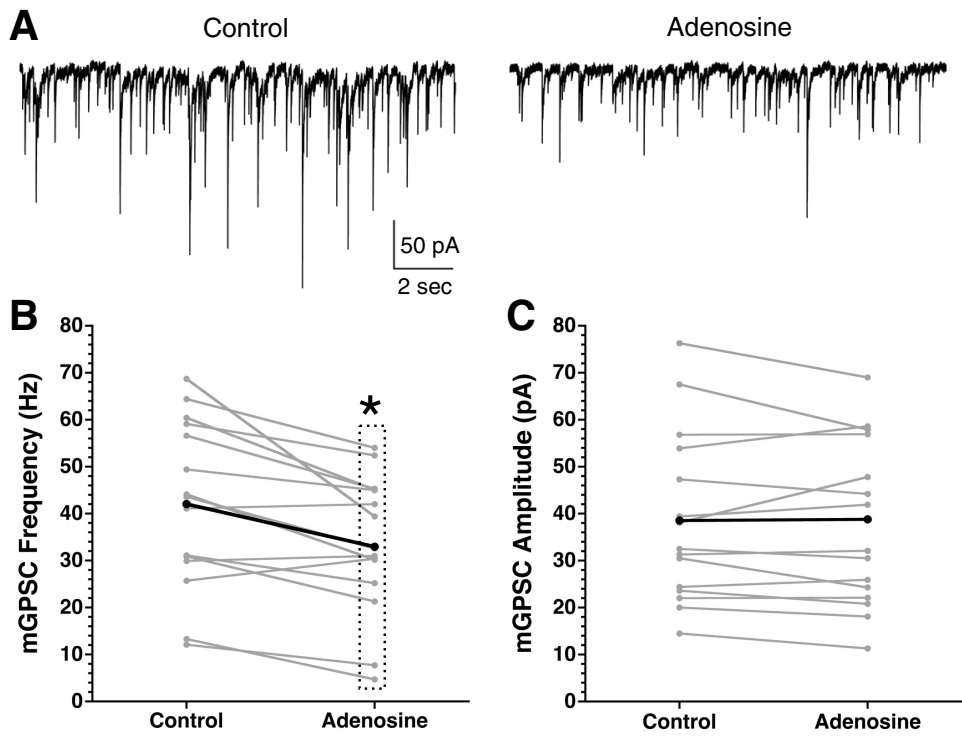

Figure 7. Adenosine decreases the mGPSC frequency. $\boldsymbol{A}$, Representative mGPSC recordings from a single SCN neuron before and during adenosine $(100 \mu \mathrm{M})$ application. Frequency $(\boldsymbol{B})$ and amplitude $(\boldsymbol{C})$ of mGPSCs before and during adenosine treatment. Gray lines are individual cells, black represents the group average; $* p=0.05$. 
A

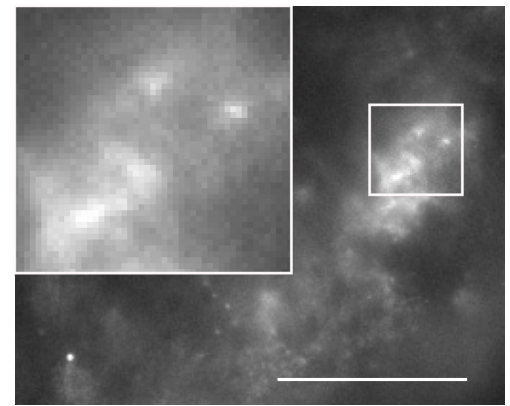

C

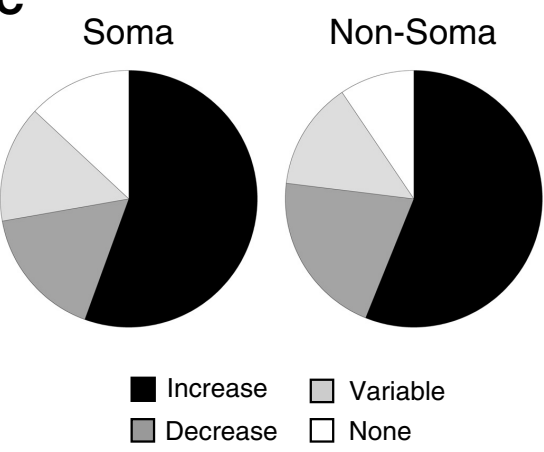

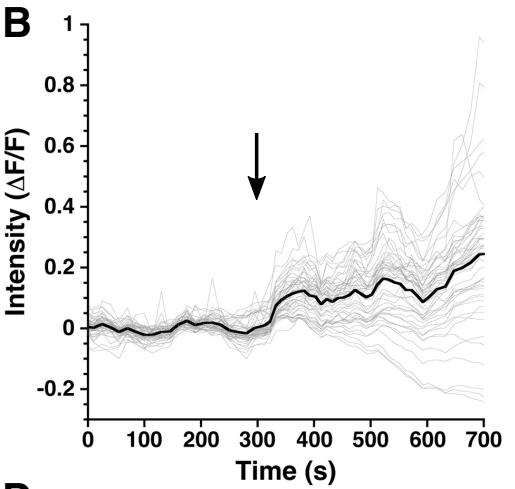

D 0.5

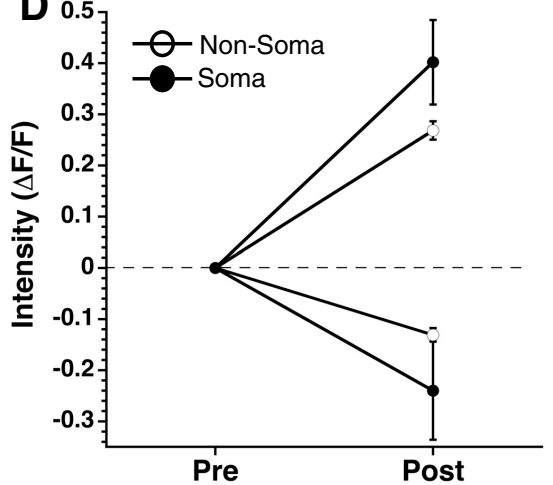

Figure 8. Activation of Gq DREADDs increases intracellular $\mathrm{Ca}^{2+}$ in astrocytes. $\boldsymbol{A}$, Representative SCN slice of a GFAP-Cre + mouse injected with Gq DREADD and GCaMP6. Scale bar is $50 \mu \mathrm{m}$, images taken at $40 \times$ and the inserts magnified $120 \times$. $\boldsymbol{B}$, Fluorescent intensity over time of the slice shown in $\boldsymbol{A}$. Black arrow indicates the CNO $(10 \mu \mathrm{M})$ application. Gray lines are individual regions, the black line is the average response of regions. $\boldsymbol{C}$, Pie charts depict the percentage of regions that increase (black), decrease (dark gray), have a variable response (light gray), or do not respond (white) to CNO treatment across all experiments. $\boldsymbol{D}$, Average fluorescent intensity before and after CNO application displayed as mean \pm SEM for soma and non-soma regions.

Table 6. Statistics for the data shown in Figures 9, 10

\begin{tabular}{|c|c|c|c|}
\hline Figure & Statistical test & Statistics output & $N$ \\
\hline $\begin{array}{l}\text { mGPSC frequency: } \\
\text { DMSO } \times \text { CNO }\end{array}$ & ANOVA & $\begin{array}{l}F_{(1,30)}=5.642 \\
p=0.024\end{array}$ & CNO: 10 neurons, 3 mice \\
\hline $\begin{array}{l}\text { mGPSC amplitude: } \\
\text { DMSO } \times \text { CNO }\end{array}$ & ANOVA & $\begin{array}{l}F_{(1,30)}=2.205 \\
p=0.148\end{array}$ & \\
\hline $\begin{array}{l}\text { mGPSC frequency: } \\
\text { DPCPX } \times \text { DPCPX }+ \text { CNO }\end{array}$ & ANOVA & $F_{(1,10)}=0.7, p=0.422$ & $\begin{array}{l}\text { CNO + DPCPX: } 12 \\
\text { neurons, } 4 \text { mice }\end{array}$ \\
\hline $\begin{array}{l}\text { mGPSC amplitude: } \\
\text { DPCPX } \times \text { DPCPX }+ \text { CNO }\end{array}$ & ANOVA & $\begin{array}{l}F_{(1,10)}=2.515 \\
p=0.144\end{array}$ & \\
\hline $\begin{array}{l}\text { mGPSC frequency: } \\
\text { DMSO } \times \text { CNOwoDREADD }\end{array}$ & ANOVA & $\begin{array}{l}F_{(1,30)}=1.334 \\
p=0.257\end{array}$ & $\begin{array}{l}\text { CNOwoDREADD: } \\
10 \text { neurons, } 3 \text { mice }\end{array}$ \\
\hline $\begin{array}{l}\text { mGPSC amplitude: } \\
\text { DMSO × CNOwoDREADD } \\
\text { Fig. } 10\end{array}$ & ANOVA & $F_{(1,30)}=0.731, p=0.4$ & \\
\hline $\begin{array}{l}\text { Phase shift: slice } \times \text { treatment } \\
(\text { control/WIN/DPCPX/WIN + DPCPX) }\end{array}$ & Repeated measures ANOVA & $\begin{array}{l}F_{(3,28)}=15.014 \\
p<0.001\end{array}$ & 8 mice per group \\
\hline $\begin{array}{l}\text { Period change WIN experiments: } \\
\text { pre and post only }\end{array}$ & Repeated Measures ANOVA & $\begin{array}{l}F_{(1,28)}=0.163 \\
p \stackrel{0}{=} 0.69\end{array}$ & 8 mice per group \\
\hline $\begin{array}{l}\text { Period change WIN experiments: } \\
\text { pre and post } \times \text { treatment }\end{array}$ & Repeated measures ANOVA & $\begin{array}{l}F_{(1,28)}=0.860 \\
p \stackrel{0}{=} 0.474\end{array}$ & 8 mice per group \\
\hline $\begin{array}{l}\text { Phase shift: slice } \times \text { treatment } \\
\text { (adenosine/control) }\end{array}$ & Repeated measures ANOVA & $\begin{array}{l}F_{(1,13.38)}=5.663 \\
p=0.032\end{array}$ & 7-11 mice per group \\
\hline $\begin{array}{l}\text { Period change adenosine: } \\
\text { pre and post only }\end{array}$ & Repeated measures ANOVA & $\begin{array}{l}F_{(1,16)}=10.816 \\
p \stackrel{0}{=} 0.005\end{array}$ & 7-11 mice per group \\
\hline $\begin{array}{l}\text { Period change adenosine: } \\
\text { pre and post } \times \text { treatment }\end{array}$ & Repeated measures ANOVA & $\begin{array}{l}F_{(1,16)}=0.568 \\
p=0.462\end{array}$ & 7-11 mice per group \\
\hline
\end{tabular}



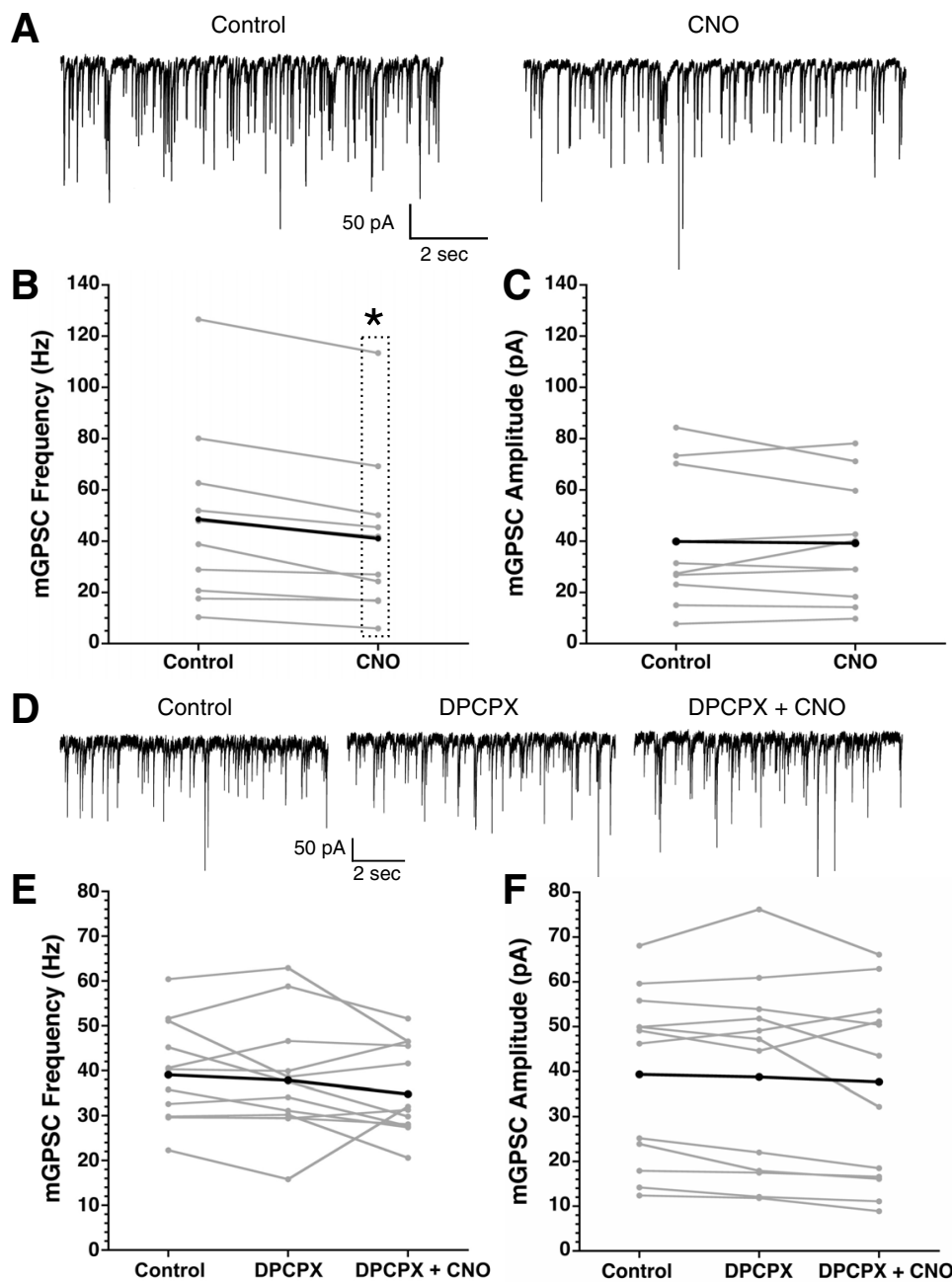

DPCPX DPCPX + CNO
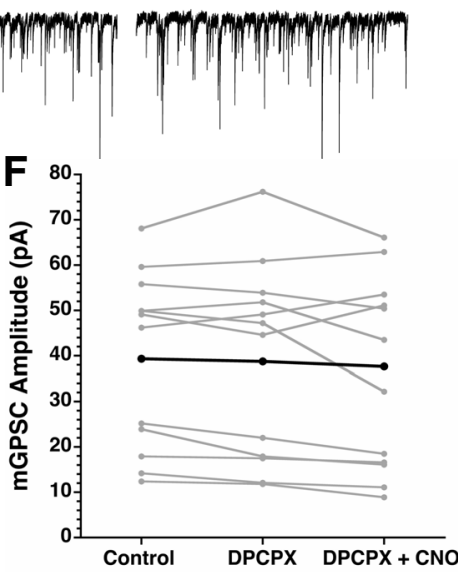

Figure 9. Astrocytic Gq DREADD activation decreases mGPSC frequency in an A1R-dependent manner. $\boldsymbol{A}$, Representative mGPSC traces before and after CNO $(10 \mu \mathrm{M})$ application from a single neuron. Frequency $(\boldsymbol{B})$ and amplitude $(\boldsymbol{C})$ of mGPSCs before and after CNO $(10 \mu \mathrm{M})$ treatment $(* p<0.05$, repeated measures analysis). Gray lines are individual neurons, the black line is the group average. $\boldsymbol{D}$, Representative mGPSC recordings before treatment, with DPCPX $(0.2 \mu \mathrm{M})$, and with both DPCPX $(0.2 \mu \mathrm{M})+\mathrm{CNO}(10 \mu \mathrm{M})$ from a single neuron. Frequency $(\boldsymbol{E})$ and amplitude $(\boldsymbol{F})$ of mGPSCs before treatment, with DPCPX, and DPCPX $+\mathrm{CNO}$. Gray lines are individual neurons, the black line is the group average.

causes a decrease in mGPSC frequency that is also dependent on A1R activation. Finally, blockade of endogenous CB1R activation with AM251 decreases both spontaneous $\mathrm{Ca}^{2+}$ events, and the number of $\mathrm{Ca}^{2+}$ events induced by depolarization of a postsynaptic neuron indicating neuronal-derived endocannabinoid signaling modulates astrocytic $\mathrm{Ca}^{2+}$ signaling in the SCN. We propose a model whereby postsynaptic neuronal activity generates endocannabinoid release, activating cannabinoid receptors on astrocytes and activating an intracellular $\mathrm{Ca}^{2+}$ signaling pathway, causing the release of adenosine and activation of A1Rs on the presynaptic neuron to decrease GABA release. Adenosine itself decreases mGPSC frequency, supporting this hypothesis. In addition to this novel model of astrocyte recruitment to modulate GABAergic signaling in the SCN, daytime application of either WIN or adenosine phase advanced PER2::LUC rhythms, indicating a conserved mechanism for modulation of circadian timing.
There are a multitude of cannabinoids, from plant derived such as cannabidiol or (-)-trans- $\Delta^{9}$-tetrahydrocannabinol found in marijuana, to endocannabinoids produced by the body such as 2-arachidonoylglycerol and anandamide, to pharmacological agents designed to activate specific cannabinoid receptors (Stella, 2010; Le Boisselier et al., 2017). The affinity of these compounds for cannabinoid receptors varies greatly (McPartland et al., 2007) and cannabinoid receptors can have multiple binding sites (Lauckner et al., 2005; McPartland et al., 2007; Khajehali et al., 2015; Hua et al., 2017). To control for these confounds, we not only activated CBRs via the potent agonist WIN, but blocked CB1Rs, specifically, with AM251 to investigate the role of endocannabinoid signaling instead of relying on observations made with exogenous cannabinoids. Conventionally, CB1Rs are identified as Gi-coupled G-protein-coupled receptors, but WIN binds CB1 in such a way that it couples to Gq G-proteins and promotes release of $\mathrm{Ca}^{2+}$ from internal stores (Lauck- 

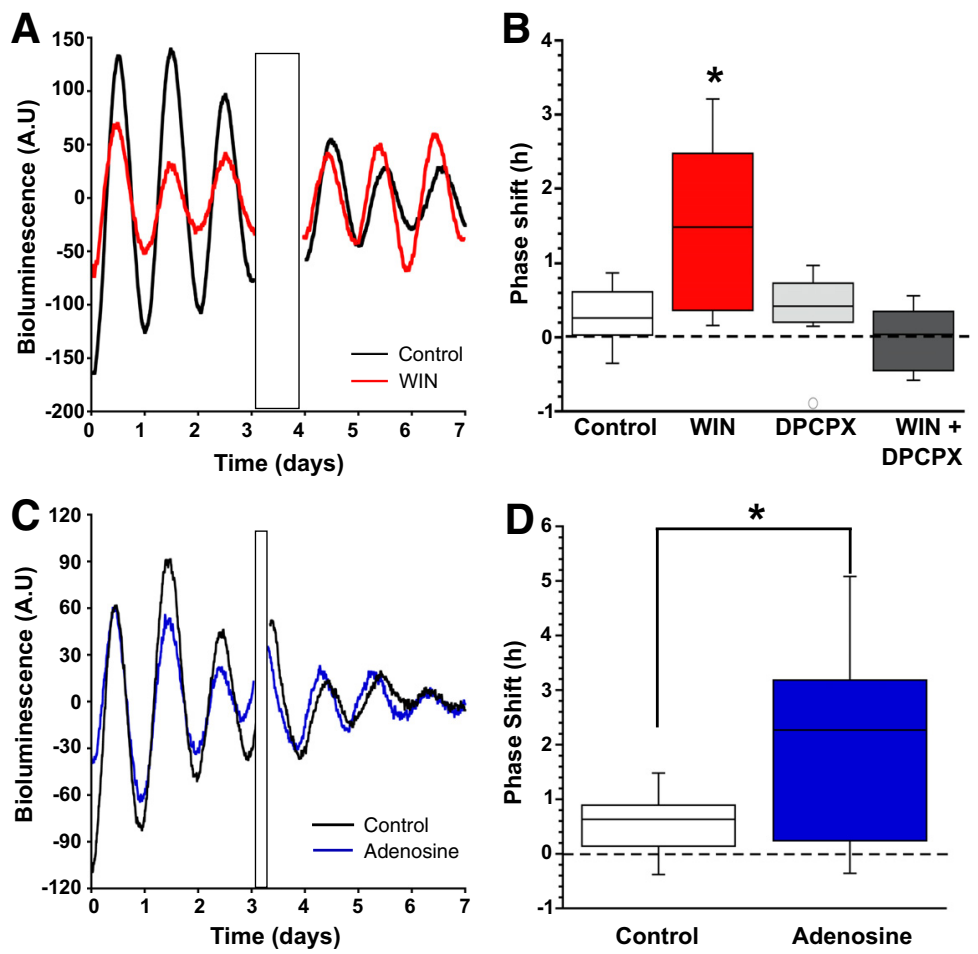

Figure 10. Daytime application of either WIN (3 $\mu \mathrm{M})$ or adenosine (100 $\mu \mathrm{M})$ phase advanced the molecular clock. $\boldsymbol{A}$, Representative bioluminescence recordings from two separate slices, one control (black) the other WIN (3 $\mu \mathrm{M})$ treated (red), over $8 \mathrm{~d}$. Treatment artifact is indicated by the black rectangle. $\boldsymbol{B}$, Box plot of phase shifts of all the cultures after treatment with either control (white) or WIN (red), DPCPX (light gray), or WIN+DPCPX (dark gray; $* p<0.05$ ). $\boldsymbol{C}$, Representative bioluminescence recordings from two separate slices, one control (black) and the other adenosine $(100 \mu \mathrm{M})$ treated (blue), over $7 \mathrm{~d}$. Treatment artifact is indicated by the black rectangle. $\boldsymbol{D}$, Box plot of phase shifts of SCN slice cultures after treatment with either control (black) or adenosine (blue; $* p<$ 0.05).

ner et al., 2005). Our data supports these findings such that the effects of WIN in the SCN are dependent on CB1R activation, Gq signaling increases astrocytic intracellular $\mathrm{Ca}^{2+}$ to a similar extent as WIN, and blockade of CB1R decreases $\mathrm{Ca}^{2+}$ events. Further work must be done to identify which endocannabinoid, specifically, is responsible for these $\mathrm{Ca}^{2+}$ events, but given the complexity of CB1R binding and function this may be difficult to discern.

Traditionally, cannabinoids act as a retrograde signal whereby after a depolarizing event a postsynaptic cell synthesizes and releases endocannabinoids that activate cannabinoid receptors on the presynaptic cell to regulate neuronal excitability (Wilson et al., 2001; Wilson and Nicoll, 2001). Our model supports previous work challenging this model, implicating astrocytes as necessary intermediates to fine tune retrograde responses (Navarrete and Araque, 2008, 2010; Min et al., 2012; Di et al., 2013; Viader et al., 2015). In the SCN, there has been growing evidence that astrocytes actively modulate neuronal function and circadian rhythmicity (Barca-Mayo et al., 2017; Brancaccio et al., 2017; Tso et al., 2017), broadening the role of astrocytes from mediating retrograde responses from neurons to actively integrating time-of-day information to the SCN network. A recent study demonstrated that astrocyte-specific deletion of BMAL1, an essential circadian gene, causes bimodal activity of animals in constant darkness. Blockade of GABA(A) over several days was able to rescue this be- havioral phenotype, indicating that astrocytes regulate GABAergic signaling (Barca-Mayo et al., 2017). The current study supports these observations, demonstrating that astrocytes are necessary for modulation of GABAergic tone. Utilizing the circadian tau mutant, where a selective deletion of a mutant form of casein kinase $\varepsilon$ in astrocytes causes a circadian period mismatch in neurons and astrocytes of 22 and $24 \mathrm{~h}$, respectively, astrocytes have been shown to influence circadian free-running period, or day length (Tso et al., 2017). Future work will investigate the ability of astrocytes to synchronize SCN neurons, perhaps via cannabinoid signaling.

We chose to study cannabinoid signaling in the SCN during the day for several reasons. First, previous work demonstrated that endocannabinoids may act as a nonphotic cue (Acuna-Goycolea et al., 2010), which are more effective during the day. Next, the endogenous CB1 agonist 2-arachidonoyl-glycerol shows a diurnal rhythm, with a peak during the day (Valenti et al., 2004; Liedhegner et al., 2014). Finally, endocannabinoid signaling is different from many transmitter signaling systems in that the endocannabinoids are synthesized on demand in response to increases in neuronal activity (Navarrete and Araque, 2008), and SCN neurons are most active during the day (Green and Gillette, 1982). Astrocytes in the SCN have increased global intracellular calcium at night, with relatively little calcium signaling during the day (Brancaccio et al., 2017; Brancaccio et al., 2019). The current 
model suggests this increased calcium at night reflects active extracellular glutamate buffering by the astrocytes via NMDAR dependent mechanisms (Brancaccio et al., 2017, 2019). Although providing an explanation to the potential roles of astrocytes in setting periodicity and neuronal activity at night, relatively little is known about astrocytic function during the day. We suggest that decreased $\left[\mathrm{Ca}^{2+}\right]_{\mathrm{i}}$ during the day fits our model, enabling astrocytes to fine-tune neuronal activity locally at synapses compared to broadly buffering glutamate across the SCN. This is supported both by AM251 and FC having no direct effect on neuronal activity and by AM251 decreasing spontaneous, local astrocytic $\left[\mathrm{Ca}^{2+}\right]_{\mathrm{i}}$, supporting our hypothesis that endogenous cannabinoid signaling in the SCN involves astrocytes. One endogenous, physiologic condition in the SCN that could induce cannabinoid signaling may be a light stimulus that excites neurons broadly over the SCN. Future work may test the hypothesis that cannabinoid signaling in astrocytes is a mechanism to fine-tune neuronal responses to light.

\section{References}

Acuna-Goycolea C, Obrietan K, van den Pol AN (2010) Cannabinoids excite circadian clock neurons. J Neurosci 30:10061-10066.

Araque A, Castillo PE, Manzoni OJ, Tonini R (2017) Synaptic functions of endocannabinoid signaling in health and disease. Neuropharmacology 124:13-24.

Barca-Mayo O, Pons-Espinal M, Follert P, Armirotti A, Berdondini L, De Pietri Tonelli D (2017) Astrocyte deletion of Bmal1 alters daily locomotor activity and cognitive functions via GABA signalling. Nat Commun 8:14336.

Beaulé C, Swanstrom A, Leone MJ, Herzog ED (2009) Circadian modulation of gene expression, but not glutamate uptake, in mouse and rat cortical astrocytes. PLoS One 4:e7476.

Bellot-Saez A, Kékesi O, Morley JW, Buskila Y (2017) Astrocytic modulation of neuronal excitability through $\mathrm{K}^{+}$spatial buffering. Neurosci Biobehav Rev 77:87-97.

Ben Achour S, Pascual O (2012) Astrocyte-neuron communication: functional consequences. Neurochem Res 37:2464-2473.

Besing RC, Hablitz LM, Paul JR, Johnson RL, Prosser RA, Gamble KL (2012) Neuropeptide Y-induced phase shifts of PER2::LUC rhythms are mediated by long-term suppression of neuronal excitability in a phase-specific manner. Chronobiol Intern 29:91-102.

Bindocci E, Savtchouk I, Liaudet N, Becker D, Carriero G, Volterra A (2017) Three-dimensional $\mathrm{Ca}^{2+}$ imaging advances understanding of astrocyte biology. Science 356:eaai8185.

Brancaccio M, Patton AP, Chesham JE, Maywood ES, Hastings MH (2017) Astrocytes control circadian timekeeping in the suprachiasmatic nucleus via glutamatergic signaling. Neuron 93:14201435.e5.

Brancaccio M, Edwards MD, Patton AP, Smyllie NJ, Chesham JE, Maywood ES, Hastings MH (2019) Cell-autonomous clock of astrocytes drives circadian behavior in mammals. Science 363:187192.

Chavas J, Marty A (2003) Coexistence of excitatory and inhibitory GABA synapses in the cerebellar interneuron network. J Neurosci 23:2019-2031.

Chen TW, Wardill TJ, Sun Y, Pulver SR, Renninger SL, Baohan A, Schreiter ER, Kerr RA, Orger MB, Jayaraman V, Looger LL, Svoboda K, Kim DS (2013) Ultrasensitive fluorescent proteins for imaging neuronal activity. Nature 499:295-300.

Di S, Popescu IR, Tasker JG (2013) Glial control of endocannabinoid heterosynaptic modulation in hypothalamic magnocellular neuroendocrine cells. J Neurosci 33:18331-18342.
Fiacco TA, Agulhon C, McCarthy KD (2009) Sorting out astrocyte physiology from pharmacology. Annu Rev Pharmacol Toxicol 49: 151-174.

Green DJ, Gillette R (1982) Circadian rhythm of firing rate recorded from single cells in the rat suprachiasmatic brain slice. Brain Res 245:198-200.

Hablitz LM, Molzof HE, Paul JR, Johnson RL, Gamble KL (2014) Suprachiasmatic nucleus function and circadian entrainment are modulated by $G$ protein-coupled inwardly rectifying (GIRK) channels. J Physiol 592:5079-5092.

Hua T, Vemuri K, Nikas SP, Laprairie RB, Wu Y, Qu L, Pu M, Korde A, Jiang S, Ho JH, Han GW, Ding K, Li X, Liu H, Hanson MA, Zhao S, Bohn LM, Makriyannis A, Stevens RC, Liu ZJ (2017) Crystal structures of agonist-bound human cannabinoid receptor CB1. Nature 547:468-471.

Irwin RP, Allen CN (2013) Simultaneous electrophysiological recording and calcium imaging of suprachiasmatic nucleus neurons. J Vis $\operatorname{Exp}(82): 50794$.

Jackson FR (2011) Glial cell modulation of circadian rhythms. Glia 59:1341-1350.

Khajehali E, Malone DT, Glass M, Sexton PM, Christopoulos A, Leach K (2015) Biased agonism and biased allosteric modulation at the CB1 cannabinoid receptor. Mol Pharmacol 88:368-379.

Klett NJ, Allen CN (2017) Intracellular chloride regulation in AVP+ and VIP+ neurons of the suprachiasmatic nucleus. Sci Rep 7:10226.

Koch M, Ferreirós N, Geisslinger G, Dehghani F, Korf HW (2015) Rhythmic control of endocannabinoids in the rat pineal gland. Chronobiol Int 32:869-874.

Lauckner JE, Hille B, Mackie K (2005) The cannabinoid agonist WIN55,212-2 increases intracellular calcium via CB1 receptor coupling to Gq/11 G proteins. Proc Natl Acad Sci USA 102:1914419149.

Le Boisselier R, Alexandre J, Lelong-Boulouard V, Debruyne D (2017) Focus on cannabinoids and synthetic cannabinoids. Clin Pharmacol Ther 101:220-229.

Liedhegner ES, Sasman A, Hillard CJ (2014) Brain region-specific changes in $\mathrm{N}$-acylethanolamine contents with time of day. J Neurochem 128:491-506.

Liu QS, Xu Q, Kang J, Nedergaard M (2004) Astrocyte activation of presynaptic metabotropic glutamate receptors modulates hippocampal inhibitory synaptic transmission. Neuron Glia Biol 1:307-316.

Losi G, Mariotti L, Carmignoto G (2014) GABAergic interneuron to astrocyte signalling: a neglected form of cell communication in the brain. Philos Trans R Soc Lond B Biol Sci 369:20130609.

Marpegan L, Krall TJ, Herzog ED (2009) Vasoactive intestinal polypeptide entrains circadian rhythms in astrocytes. J Biol Rhythms 24:135-143.

Marpegan L, Swanstrom AE, Chung K, Simon T, Haydon PG, Khan SK, Liu AC, Herzog ED, Beaulé C (2011) Circadian regulation of ATP release in astrocytes. J Neurosci 31:8342-8350.

McPartland JM, Glass M, Pertwee RG (2007) Meta-analysis of cannabinoid ligand binding affinity and receptor distribution: interspecies differences. Br J Pharmacol 152:583-593.

Min R, Santello M, Nevian T (2012) The computational power of astrocyte mediated synaptic plasticity. Front Comput Neurosci 6:93.

Metna-Laurent M, Marsicano G (2015) Rising stars: modulation of brain functions by astroglial type- 1 cannabinoid receptors. Glia 63:353-364.

Mohawk JA, Takahashi JS (2011) Cell autonomy and synchrony of suprachiasmatic nucleus circadian oscillators. Trends Neurosci 34:349-358.

Moldavan M, Cravetchi O, Williams M, Irwin RP, Aicher SA, Allen CN (2015) Localization and expression of GABA transporters in the suprachiasmatic nucleus. Eur J Neurosci 42:3018-3032.

Morin LP, Hefton S, Studholme KM (2011) Neurons identified by NeuN/Fox-3 immunoreactivity have a novel distribution in the 
hamster and mouse suprachiasmatic nucleus. Brain Res 1421:4451.

Navarrete M, Araque A (2008) Endocannabinoids mediate neuronastrocyte communication. Neuron 57:883-893.

Navarrete M, Araque A (2010) Endocannabinoids potentiate synaptic transmission through stimulation of astrocytes. Neuron 68:113126.

Nishiyama A, Komitova M, Suzuki R, Zhu X (2009) Polydendrocytes (NG2 cells): multifunctional cells with lineage plasticity. Nat Rev Neurosci 10:9-22.

Ohno-Shosaku T, Maejima T, Kano M (2001) Endogenous cannabinoids mediate retrograde signals from depolarized postsynaptic neurons to presynaptic terminals. Neuron 29:729-738.

Perea G, Araque A (2007) Astrocytes potentiate transmitter release at single hippocampal synapses. Science 317:1083-1086.

Poskanzer KE, Yuste R (2016) Astrocytes regulate cortical state switching in vivo. Proc Natl Acad Sci USA 113:E2675-E2684.

Pirttimaki TM, Parri HR (2013) Astrocyte plasticity: implications for synaptic and neuronal activity. Neuroscientist 19:604-615.

Rogan SC, Roth BL (2011) Remote control of neuronal signaling. Pharmacol Rev 63:291-315.

Rusakov DA (2015) Disentangling calcium-driven astrocyte physiology. Nat Rev Neurosci 16:226-233.

Sanford AE, Castillo E, Gannon RL (2008) Cannabinoids and hamster circadian activity rhythms. Brain Res 1222:141-148.

Shigetomi E, Bushong EA, Haustein MD, Tong X, Jackson-Weaver O, Kracun S, Xu J, Sofroniew MV, Ellisman MH, Khakh BS (2013) Imaging calcium microdomains within entire astrocyte territories and endfeet with GCaMPs expressed using adeno-associated viruses. J Gen Physiol 141:633-647.

Shigetomi E, Patel S, Khakh BS (2016) Probing the complexities of astrocyte calcium signaling. Trends Cell Biol 26:300-312.

Sonnay S, Poirot J, Just N, Clerc AC, Gruetter R, Rainer G, Duarte JMN (2018) Astrocytic and neuronal oxidative metabolism are coupled to the rate of glutamate glutamine cycle in the tree shrew visual cortex. Glia 66:477-491.

Stella N (2010) Cannabinoid and cannabinoid-like receptors in microglia, astrocytes, and astrocytomas. Glia 58:1017-1030.

Svobodova I, Bhattaracharya A, Ivetic M, Bendova Z, Zemkova H (2018) Circadian ATP release in organotypic cultures of the rat suprachiasmatic nucleus is dependent on $\mathrm{P} 2 \mathrm{X} 7$ and $\mathrm{P} 2 \mathrm{Y}$ receptors. Front Pharmacol 9:192.
Takata N, Sugiura Y, Yoshida K, Koizumi M, Hiroshi N, Honda K, Yano R, Komaki Y, Matsui K, Suematsu M, Mimura M, Okano H, Tanaka KF (2018) Optogenetic astrocyte activation evokes BOLD fMRI response with oxygen consumption without neuronal activity modulation. Glia 66:2013-2023.

Tong X, Shigetomi E, Looger LL, Khakh BS (2013) Genetically encoded calcium indicators and astrocyte calcium microdomains. Neuroscientist 19:274-291.

Tso CF, Simon T, Greenlaw AC, Puri T, Mieda M, Herzog ED (2017) Astrocytes regulate daily rhythms in the suprachiasmatic nucleus and behavior. Curr Biol 27:1055-1061.

Valenti M, Viganò D, Casico MG, Rubino T, Steardo L, Parolaro D, Di Marzo V (2004) Differential diurnal variations of anandamide and 2-arachidonoyl-glycerol levels in rat brain. Cell Mol Life Sci 61: 945-950.

Viader A, Blankman JL, Zhong P, Liu X, Schlosburg JE, Joslyn CM, Liu QS, Tomarchio AJ, Lichtman AH, Selley DE, Sim-Selley LJ, Cravatt BF (2015) Metabolic interplay between astrocytes and neurons regulates endocannabinoid action. Cell Rep 12:798-808.

Waseem T, Mukhtarov M, Buldakova S, Medina I, Bregestovski P (2010) Genetically encoded $\mathrm{Cl}$-Sensor as a tool for monitoring of $\mathrm{Cl}$-dependent processes in small neuronal compartments. J Neurosci Methods 193:14-23.

Welsh DK, Takahashi JS, Kay SA (2010) Suprachiasmatic nucleus: cell autonomy and network properties. Annu Rev Physiol 72:551577.

Wilson RI, Nicoll RA (2001) Endogenous cannabinoids mediate retrograde signalling at hippocampal synapses. Nature 410:588-592.

Wilson RI, Kunos G, Nicoll RA (2001) Presynaptic specificity of endocannabinoid signaling in the hippocampus. Neuron 31:453462.

Woodin MA, Ganguly K, Poo MM (2003) Coincident pre- and postsynaptic activity modifies GABAergic synapses by postsynaptic changes in Cl- transporter activity. Neuron 39:807-820.

Yamashiro K, Fujii Y, Maekawa S, Morita M (2017) Multiple pathways for elevating extracellular adenosine in the rat hippocampal CA1 region characterized by adenosine sensor cells. J Neurochem 140:24-36

Yoo SH, Yamazaki S, Lowrey PL, Shimomura K, Ko CH, Buhr ED, Siepka SM, Hong HK, Oh WJ, Yoo OJ, Menaker M, Takahashi JS (2004) PERIOD2::LUCIFERASE real-time reporting of circadian dynamics reveals persistent circadian oscillations in mouse peripheral tissues. Proc Natl Acad Sci USA 101:5339-5346. 